\title{
Combination of Au-Ag Plasmonic Nanoparticles of Varied Compositions with Carbon Nitride for Enhanced Photocatalytic Degradation of Ibuprofen under Visible Light
}

\author{
Marta Jiménez-Salcedo, Miguel Monge *(D) and María Teresa Tena \\ Centro de Investigación en Síntesis Química (CISQ), Department of Chemistry, University of La Rioja, \\ Complejo Científico-Tecnológico, 26006 Logrono, Spain; marta.jimenez@unirioja.es (M.J.-S.); \\ maria-teresa.tena@unirioja.es (M.T.T.) \\ * Correspondence: miguel.monge@unirioja.es
}

check for

updates

Citation: Jiménez-Salcedo, M.; Monge, M.; Tena, M.T. Combination of Au-Ag Plasmonic Nanoparticles of Varied Compositions with Carbon Nitride for Enhanced Photocatalytic Degradation of Ibuprofen under Visible Light. Materials 2021, 14, 3912. https://doi.org/10.3390/ma14143912

Academic Editor: Arunas

Ramanavicius

Received: 3 June 2021

Accepted: 8 July 2021

Published: 14 July 2021

Publisher's Note: MDPI stays neutral with regard to jurisdictional claims in published maps and institutional affiliations.

Copyright: (c) 2021 by the authors. Licensee MDPI, Basel, Switzerland. This article is an open access article distributed under the terms and conditions of the Creative Commons Attribution (CC BY) license (https:/ / creativecommons.org/licenses/by/ $4.0 /)$.
Abstract: $\mathrm{Au}-\mathrm{Ag} / \mathrm{g}-\mathrm{C}_{3} \mathrm{~N}_{4}$ nanohybrids 2-3 were synthesized by the one-pot self-reduction of the organometallic precursor $\left[\mathrm{Au}_{2} \mathrm{Ag}_{2}\left(\mathrm{C}_{6} \mathrm{~F}_{5}\right)_{4}\left(\mathrm{OEt}_{2}\right)_{2}\right]_{\mathrm{n}}$ in the presence of graphitic carbon nitride $\left(\mathrm{g}-\mathrm{C}_{3} \mathrm{~N}_{4}\right.$ ), leading to two populations of alloyed Au-Ag nanoparticles (NPs) of different size and composition on the surface of $\mathrm{g}-\mathrm{C}_{3} \mathrm{~N}_{4}$, i.e., Ag-enriched Au-Ag NPs of smaller size and Au-enriched $\mathrm{Au}-\mathrm{Ag}$ NPs of larger size. The combination of these two types of plasmonic NPs with $\mathrm{g}-\mathrm{C}_{3} \mathrm{~N}_{4}$ semiconductor displays enhanced photocatalytic properties towards the degradation of ibuprofen under visible light by the increased charge carrier separation provided by the inclusion of the plasmonic NPs on $g-\mathrm{C}_{3} \mathrm{~N}_{4}$.

Keywords: gold; silver; carbon nitride; nanostructures; ibuprofen; photocatalysis; visible light

\section{Introduction}

During the last years the search for efficient photocatalytic materials designed for sustainable applications such as photovoltaic devices, water splitting, photocatalytic chemical transformations or degradation of pollutants have attracted wide attention [1,2]. Extensive research on the development and applications of titania-based semiconductor photocatalysts under ultraviolet light has been carried out since the 1970s [3], but their lack of or reduced use of visible light, which is the main component of solar radiation on Earth, has prompted the research community to focus on the development of new visible light-active materials as efficient photocatalysts [4-6]. At this regard, taking into account that the solar light is formed by ultraviolet (UV) (5\%), visible (43\%) and infrared (IR) (52\%) components, many of the known photocatalysts present low overall solar energy utilization [7], making the design of novel photocatalysts displaying high efficiencies under visible or near infrared (NIR) light excitation and their use in the degradation of water pollutants a very challenging issue [8].

Among the wide family of semiconductors used in photocatalysis for the degradation of pollutants the narrow band-gap semiconductor graphitic carbon nitride $\left(g-\mathrm{C}_{3} \mathrm{~N}_{4}\right)$ has emerged as an outstanding material due to a number of interesting features [9], namely: (i) visible light response (band-gap of ca. $2.7 \mathrm{eV}$ ); (ii) a sheet-like nanostructure displaying a high surface to volume ratio; (iii) thermal and chemical stability; (iv) good adsorption ability and (v) facile synthesis. However, this material also displays important drawbacks such as a narrow visible light absorption window or the fast recombination of charge carriers.

A smart approach to overcome these disadvantages consists of the formation or deposition of noble gold $(\mathrm{Au})$ or silver $(\mathrm{Ag})$ or even to a lesser extent bimetallic $\mathrm{Au}-\mathrm{Ag}$ metal nanoparticles (NPs) on the surface of $\mathrm{g}-\mathrm{C}_{3} \mathrm{~N}_{4}$ nanosheets [10,11]. These hybrid nanosystems constitute a unique challenge in which the catalytic, electronic and optical properties of the metal nanoparticles are combined with the abovementioned ones provided by the 
g- $\mathrm{C}_{3} \mathrm{~N}_{4}$ nanosheets. Indeed, on the one hand these metals display strong size and shapedependent light absorption in the visible or NIR ranges due to the localized surface plasmon resonance effect (LSPR) [12-15], i.e., the resonant oscillation of conduction electrons in response to an oscillating electric field from an incident electromagnetic radiation [16-18]. This effect has given rise to the study of interesting related properties such as plasmonic photocatalysis, plasmon-enhanced fluorescence, surface enhanced Raman scattering (SERS) or photothermal heating [19]. The combination of these plasmonic NPs with g- $\mathrm{C}_{3} \mathrm{~N}_{4}$ allows one to synergistically overcome some of the main drawbacks of the pristine semiconductor. Thus, LSPR effects such as local heating, near-field effect or charge-transfer processes of plasmonically excited electrons (hot electrons) to the semiconductor cut out to a large extent the electron-hole recombination [20]. On the other hand, and very importantly, when noble metal NPs are grafted at the semiconductor surface a contact potential is formed in the heterojunction, which is called the Schottky barrier. This energy barrier enables a unidirectional transfer of photogenerated electrons in the semiconductor to the metal NPs, which act as electron sinks, leading to a very effective charge carrier separation [21]. This enhanced charge carrier separation greatly favors the formation of reactive oxygen species (ROS), leading to an improved photocatalytic performance.

There are several approaches for the synthesis of metal NPs-g- $\mathrm{C}_{3} \mathrm{~N}_{4}$ nanohybrids, which include pulsed laser ablation, hydro/solvothermal techniques, microwave assisted synthesis, chemical reduction, wet impregnation/calcination or photodeposition, being the latter the most convenient approach [11].

We have focused a part of our research efforts on the synthesis of bimetallic $\mathrm{Au}-\mathrm{Ag}$ plasmonic nanostructures through an organometallic approach. This method consists of the self-reduction under mild reaction conditions of pentafluorophenyl-based precursors through a bimolecular reductive elimination mechanism, which allows one to exert an excellent control over the size, shape, composition and surface state of the NPs. In order, to exert this control, different types of capping agents such as long-alkyl chain ligands [22] or polymers can be used [23]. However, the use of these growth directing agents usually prevents the utilization of such nanostructures as (photo)catalysts, although they present interesting tunable plasmonic properties. In addition, a previous study by some of us on the UV-vis time-monitored formation of alloy Au-Ag NPs by decomposition of complex $\left[\mathrm{Au}_{2} \mathrm{Ag}_{2}\left(\mathrm{C}_{6} \mathrm{~F}_{5}\right)_{4}\left(\mathrm{OEt}_{2}\right)_{2}\right]_{\mathrm{n}}$ in the presence of hexadecylamine as capping ligand [22], showed that this decomposition was sequential, starting from less stable $\mathrm{Ag}(\mathrm{I})$ intermediates and followed by $\mathrm{Au}(\mathrm{I})$ ones, formed in situ. This approach allowed the synthesis of $\mathrm{Au}-\mathrm{Ag}$ NPs with distinct metal contents, leading to a tuning of the plasmonic properties.

At this point we wondered whether this controlled sequential decomposition of the organometallic precursor $\left[\mathrm{Au}_{2} \mathrm{Ag}_{2}\left(\mathrm{C}_{6} \mathrm{~F}_{5}\right)_{4}\left(\mathrm{OEt}_{2}\right)_{2}\right]_{\mathrm{n}}$ would give rise to the formation of composition-controlled $\mathrm{Au}-\mathrm{Ag}$ NPs stabilized at the surface of $\mathrm{g}-\mathrm{C}_{3} \mathrm{~N}_{4}$, without the concurrence of any other growth directing ligand or polymer, leading to small-size plasmonic nanoparticles of different gold/silver content efficiently grafted to the surface of g- $C_{3} \mathrm{~N}_{4}$. This approach would provide several advantages, namely: (i) the triazine groups of $\mathrm{g}$ $\mathrm{C}_{3} \mathrm{~N}_{4}$ would be able to stabilize Au-Ag NPs of different compositions formed during their sequential formation, (ii) a broader plasmonic absorption arising from the different $\mathrm{Au}-\mathrm{Ag}$ NP compositions would be obtained, increasing the visible-light absorption ability and improving LSPR effects upon excitation with broad-range visible light and (iii) AuAg NPs of different compositions may act as electron sinks of photogenerated electrons improving the charge carrier and enhancing the photocatalytic performance towards the degradation of pharmaceuticals.

Herein we report the synthesis and in-depth characterization of plasmonic $\mathrm{Au}-\mathrm{Ag} / \mathrm{g}$ $\mathrm{C}_{3} \mathrm{~N}_{4}$ nanohybrids by the direct formation of alloy Au-Ag NPs of different compositions at the surface of $2 \mathrm{D} \mathrm{g}-\mathrm{C}_{3} \mathrm{~N}_{4}$ nanosheets. We have also checked the photocatalytic performance of these NPs in the degradation of ibuprofen, including a study of the photocatalytic degradation mechanism. 


\section{Materials and Methods}

\subsection{Materials and Reagents}

Ibuprofen, tert-butanol and triethanolamine were obtained from Sigma Aldrich (Schnelldorf, Germany). Melamine (99\%) was provided by Alfa Aesar (Kandel, Germany). HPLCgrade acetonitrile was purchased from Scharlab (Barcelona, Spain) and formic acid (98\% $v / v$ ) for mass spectrometry from Fluka Analytical (Buchs, Switzerland). Ethylene glycol and ethanol, used in the synthesis of nanoparticles, were provided from Sigma Aldrich and Panreac (Barcelona, Spain), respectively. All chemicals were used as received and no further purification was needed. The precursor $\left[\mathrm{Au}_{2} \mathrm{Ag}_{2}\left(\mathrm{C}_{6} \mathrm{~F}_{5}\right)_{4}\left(\mathrm{OEt}_{2}\right)_{2}\right]_{\mathrm{n}}$ used for the synthesis of bimetallic AuAg NPs was synthesized by standard procedures reported in [24].

\subsection{Synthesis of Photocatalysts}

2.2.1. Synthesis of $g-\mathrm{C}_{3} \mathrm{~N}_{4}$ Nanosheets (1)

The preparation of the $\mathrm{g}-\mathrm{C}_{3} \mathrm{~N}_{4}$ powder was performed by the polycondensation of melamine. Melamine $(5 \mathrm{~g})$ was thermally treated in an oven at $500{ }^{\circ} \mathrm{C}$ for $4 \mathrm{~h}$ and then, the temperature was raised to $520^{\circ} \mathrm{C}$ for $2 \mathrm{~h}$ in order to obtain exfoliated g- $\mathrm{C}_{3} \mathrm{~N}_{4}$ nanosheets, as reported previously [25]. The reaction was carried out in a covered crucible in order to prevent partially the sublimation of the precursor.

\subsubsection{Synthesis of $0.5 \%$ Au-Ag-g- $\mathrm{C}_{3} \mathrm{~N}_{4}$ Nanohybrid (2)}

To a $30 \mathrm{~min}$ sonicated $(40 \mathrm{kHz}$ and $150 \mathrm{~W})$ suspension of $\mathrm{g}-\mathrm{C}_{3} \mathrm{~N}_{4}(0.4253 \mathrm{~g})$ in $5 \mathrm{~mL}$ of ethylene glycol, $0.5 \mathrm{wt} \%$ (metal content) $\left[\mathrm{Au}_{2} \mathrm{Ag}_{2}\left(\mathrm{C}_{6} \mathrm{~F}_{5}\right)_{4}\left(\mathrm{OEt}_{2}\right)_{2}\right]_{\mathrm{n}}\left(5 \mathrm{mg}, 3.51 \times 10^{-3} \mathrm{mmol}\right)$ was added and sonicated for $3 \mathrm{~min}$. The suspension was stirred and heated under reflux at $130{ }^{\circ} \mathrm{C}$, in dark conditions, during $15 \mathrm{~min}$. After that, the formed nanohybrid was filtered and washed with ethanol. Finally, it was dried under reduced pressure, leading to a pale brownish solid.

\subsubsection{Synthesis of $1 \% \mathrm{Au}-\mathrm{Ag}-\mathrm{g}-\mathrm{C}_{3} \mathrm{~N}_{4}$ Nanohybrid (3)}

To a $30 \mathrm{~min}$ sonicated $(40 \mathrm{kHz}$ and $150 \mathrm{~W})$ suspension of $\mathrm{g}-\mathrm{C}_{3} \mathrm{~N}_{4}(0.2116 \mathrm{~g})$ in $5 \mathrm{~mL}$ of ethyleneglycol, $1 \mathrm{wt} \%$ (metal content) $\left[\mathrm{Au}_{2} \mathrm{Ag}_{2}\left(\mathrm{C}_{6} \mathrm{~F}_{5}\right)_{4}\left(\mathrm{OEt}_{2}\right)_{2}\right]_{\mathrm{n}}\left(5 \mathrm{mg}, 3.51 \times 10^{-3} \mathrm{mmol}\right)$ was added and sonicated for $3 \mathrm{~min}$. The suspension was stirred and heated under reflux at $130{ }^{\circ} \mathrm{C}$, in dark conditions, during $15 \mathrm{~min}$. After that, the formed nanohybrid was filtered and washed with ethanol. Finally, it was dried under reduced pressure, leading to a pale brownish solid.

\subsection{Characterization}

The NMR spectra were recorded on a Avance 400 spectrometer (Bruker, Billerica, MA, USA) in THF- $\mathrm{d}_{8}$ solutions. Chemical shifts are expressed relative to $\mathrm{CFCl}_{3}\left({ }^{19} \mathrm{~F}\right.$ external reference). Diffuse reflectance UV-vis spectra of pressed powder samples diluted with silica were recorded on a UV-3600 spectrophotometer (Shimadzu, Kioto, Japan) equipped with a Harrick Praying Mantis accessory and recalculated following the Kubelka-Munk function. Samples for Transmission Electron Microscopy (TEM) were directly drop-casted from the ethanol dispersions ( $2-3$ drops) to carbon-coated $\mathrm{Cu}$ grids. The TEM images were obtained with a JEM 2100 microscope (JEOL, Tokyo, Japan). High Angle Annular Dark Field-Scanning Transmission Electron Microscopy (HAADF-STEM) images were obtained in a Tecnai F30 (ThermoFisher Scientific, Waltham, MA, USA) or in a Cs-probe-corrected Titan (ThermoFisher Scientific, Waltham, MA, USA) instrument at a working voltage of $300 \mathrm{kV}$, coupled with a HAADF detector (Fischione, Export, PA, USA). In this mode, the intensity of the signal is proportional to the square of the atomic number (Z2), therefore heavier elements appear with a much brighter contrast than lighter elements, like carbon or silicon. It is especially useful to localize metals in organic matrixes. Also, in order to analyze the chemical composition of the materials, X-ray Energy Dispersive Spectra (EDS) were obtained with an EDAX detector or with an Ultim Max detector (Oxford, Oxford, Abingdon, UK). XPS experiments were performed on an AXIS Supra spectrometer (Kratos, 
Manchester, UK) using a monochromatized $\mathrm{Al} \mathrm{Ka} \mathrm{source} \mathrm{(1486.6} \mathrm{eV)} \mathrm{operating} \mathrm{at} 12 \mathrm{kV}$ and $10 \mathrm{~mA}$. Wide scans were acquired at analyzer pass energy of $160 \mathrm{eV}$, whereas highresolution narrow scans were performed at constant pass energy of $20 \mathrm{eV}$ and steps of $0.1 \mathrm{eV}$. The photoelectrons were detected at a take-off angle of $\mathrm{F}=0^{\circ}$ with respect to the surface normal. Basal pressure in the analysis chamber was less than $5 \times 10^{-9}$ Torr. The spectra were obtained at room temperature. The binding energy $(\mathrm{BE})$ scale was internally referenced to the $\mathrm{C} 1 \mathrm{~s}$ peak ( $\mathrm{BE}$ for $\mathrm{C}-\mathrm{C}=284.9 \mathrm{eV}$ ).

\subsection{Photocatalytic Activity Measurement}

In a typical ibuprofen photodegradation process, $134.5 \mathrm{mg}$ of photocatalyst was suspended in $50 \mathrm{~mL}$ of a solution of ibuprofen in ultrapure water with a concentration of $5 \mu \mathrm{g} \mathrm{mL} \mathrm{m}^{-1}$ in a Schlenk tube glass reactor. Before starting the photocatalytic reactions, the suspensions were sonicated for $2 \mathrm{~min}$, following by $40 \mathrm{~min}$ of stirring in dark conditions to reach adsorption/desorption equilibrium in the aqueous solution.

Ibuprofen solutions were irradiated with visible light radiation in a cooled lab-made setup. The assembly consists of four $10 \mathrm{~W}$ white light LED lamps (LED-Engin, San Jose, CA, USA) arranged equidistantly inside a cylinder. Water recirculating coolant coil is placed on the outside to maintain constant temperature $\left(25^{\circ} \mathrm{C}\right)$ of the glass reactor.

In addition, we performed a series of experiments using natural sunlight in order to compare the performance of the catalysts 1-3 under these conditions using ibuprofen as wastewater pollutant. These experiments were carried out with an average temperature of $28^{\circ} \mathrm{C}$ and an ultraviolet index of 7 accordingly with the Spanish National Agency of Meteorology (www.AEMET.es, accessed on 4 September 2020).

Photocatalytic reactions were performed stirring at natural $\mathrm{pH} 1.5 \mathrm{~mL}$ sample was taken regularly and filtered before analysis with nylon syringe filter $13 \mathrm{~mm}, 0.22 \mu \mathrm{m}$. Samples were stored at $4{ }^{\circ} \mathrm{C}$ until analysis by HPLC-UV.

\subsection{Photodegradation Analysis}

The ibuprofen concentration was analyzed using an Agilent modular 1100/1200 liquid chromatography system (Agilent Technologies, Palo Alto, CA, USA) equipped with a G1329A autosampler and a G1315D diode array detector and a Phenomenex Luna ${ }^{\circledR}$ LC C18 $100 \AA$ ( $5 \mu \mathrm{m}$ particle size, $150 \mathrm{~mm} \times 4.6 \mathrm{~mm}$ i.d.) column. The mobile phase consisted of a 70:30 mixture of $0.1 \%$ formic acid in acetonitrile and $0.1 \%$ formic acid aqueous solution with a flow rate of $1.0 \mathrm{~mL} / \mathrm{min}$ and an injection volume of $20 \mu \mathrm{L}$. Detection wavelengths were $220 \mathrm{~nm}$.

\subsection{Detection of Active Species in the Photocatalysis}

To study the effect of active species responsible for the photodegradation using the catalyst doped with $\mathrm{Au}-\mathrm{Ag}$, the corresponding scavengers were introduced in a typical degradation to quench the specific reactive species: tert-butanol $(1 \mathrm{mM})$ for $\mathrm{OH}$ radicals, triethanolamine $(1 \mathrm{mM})$ to quench the holes $\left(\mathrm{h}^{+}\right)$and the reaction was performed under $\mathrm{N}_{2}$ atmosphere for $\cdot \mathrm{O}_{2}{ }^{-}$quenching. These experiments were performed using the white light source from four $10 \mathrm{~W}$ white light LED lamps.

\section{Results and Discussion}

\subsection{Synthesis and Characterization of Photocatalysts}

In this work we have pursued the synthesis of AuAg-g- $\mathrm{C}_{3} \mathrm{~N}_{4}$ nanohybrids 2-3 by the decomposition of the organometallic complex $\left[\mathrm{Au}_{2} \mathrm{Ag}_{2}\left(\mathrm{C}_{6} \mathrm{~F}_{5}\right)_{4}\left(\mathrm{OEt}_{2}\right)_{2}\right]_{\mathrm{n}}(0.5 \mathrm{wt} \%$ of added metal content in the Au-Ag precursor (2) or $1 \mathrm{wt} \%$ (3)) over $\mathrm{g}-\mathrm{C}_{3} \mathrm{~N}_{4}$ sheets at $130{ }^{\circ} \mathrm{C}$ in ethyleneglycol as solvent and co-reducing agent.

This novel approach provides the possibility of taking advantage of the presence of $\mathrm{N}$-donor atoms in the triazine groups of the g- $\mathrm{C}_{3} \mathrm{~N}_{4}$ nanosheets to effectively stabilize sub$10 \mathrm{~nm}$ size $\mathrm{Au}-\mathrm{Ag}$ NPs at their surfaces without the participation of additional stabilizing ligands or polymers (see Scheme 1), leading to partially ligand-free metal surfaces. 


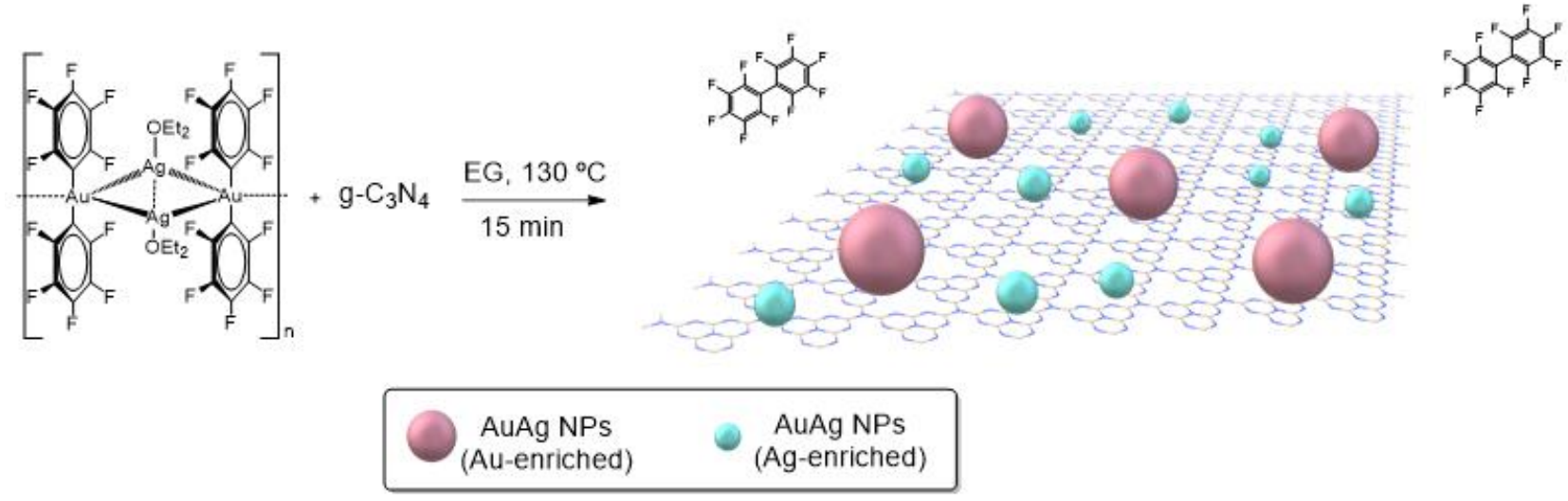

Scheme 1. Synthesis of AuAg-g- $C_{3} N_{4}$ nanohybrids 2 and 3 by reduction of complex $\left[\mathrm{Au}_{2} \mathrm{Ag}_{2}\left(\mathrm{C}_{6} \mathrm{~F}_{5}\right)_{4}\left(\mathrm{OEt}_{2}\right)_{2}\right]_{\mathrm{n}}$ in ethyleneglycol (EG) at $130^{\circ} \mathrm{C}$.

Figure 1 depicts TEM images of the formed AuAg-g- $\mathrm{C}_{3} \mathrm{~N}_{4}$ nanohybrids $2-\mathbf{3}$. The low magnification images (Figure 1A,B) show the two homogeneous distributions of spherical NPs of $2.4 \pm 1.1 \mathrm{~nm}$ and $5.0 \pm 0.6 \mathrm{~nm}$ size for 2 and $3.0 \pm 0.6 \mathrm{~nm}$ and $9.8 \pm 0.6 \mathrm{~nm}$ size for 3 (see size histograms in Supplementary Materials), which are grafted on the surface of g- $\mathrm{C}_{3} \mathrm{~N}_{4}$ nanosheets. The HRTEM images (Figure 1C,D) show polycrystalline nanoparticles of both sizes in 3 with the d spacing between lattice fringes of $0.24 \mathrm{~nm}$ that is assigned to (111) planes of gold or silver. In addition, the HRETM clearly shows the capping effect of $\mathrm{g}-\mathrm{C}_{3} \mathrm{~N}_{4}$ nanosheets that surround the nanoparticle.

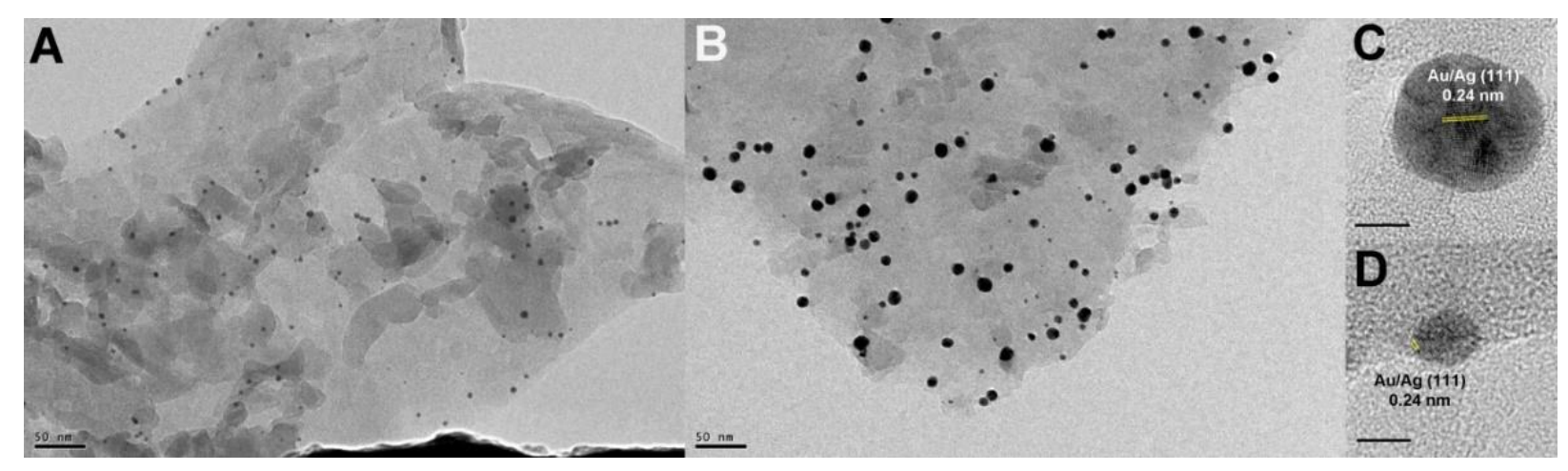

Figure 1. TEM images of AuAg-g- $\mathrm{C}_{3} \mathrm{~N}_{4}$ nanohybrid 2 (A) and 3 (B). HRTEM images for ca. $10 \mathrm{~nm}$ size NPs in 3 (bar corresponds to $5 \mathrm{~nm}$ ) (C) and ca. $3 \mathrm{~nm}$ size NPs in 3 (bar corresponds to $5 \mathrm{~nm}$ ) (D).

The presence of two types of spherical NPs grafted at the surface of $g-\mathrm{C}_{3} \mathrm{~N}_{4}$ prompted us to carry out an in-depth study of their composition through a HAADF-STEM/EDS study of a sample of AuAg-g- $\mathrm{C}_{3} \mathrm{~N}_{4}$ nanohybrid 3. Figure 2A shows HAADF-STEM image of 3 in which the $2 \mathrm{D}$ nature of $\mathrm{g}-\mathrm{C}_{3} \mathrm{~N}_{4}$ nanosheets is observed together with the presence of small size NPs with a high Z-contrast. The EDS analysis of a portion of the sample is depicted in Figure 2B-G.

The homogeneous distribution of $\mathrm{N}$ and $\mathrm{C}$ atoms along the whole sample points to the presence of $\mathrm{g}-\mathrm{C}_{3} \mathrm{~N}_{4}$ nanosheets. It is worth mentioning that oxygen is also homogeneously distributed over carbon nitride pointing to an interesting modification of its surface upon thermal treatment in the presence of ethylene glycol (vide infra). Also, interestingly, the distribution of $\mathrm{Au}$ and $\mathrm{Ag}$ along the sample does not match at the same positions, pointing to the formation of Au-enriched spherical NPs of ca. $10 \mathrm{~nm}$ size (yellow-mapped color in Figure 2C), whereas Ag atoms are more broadly distributed in the form of smaller size nanoparticles around the gold ones and over the whole carbon nitride surface (Figure 2D). 


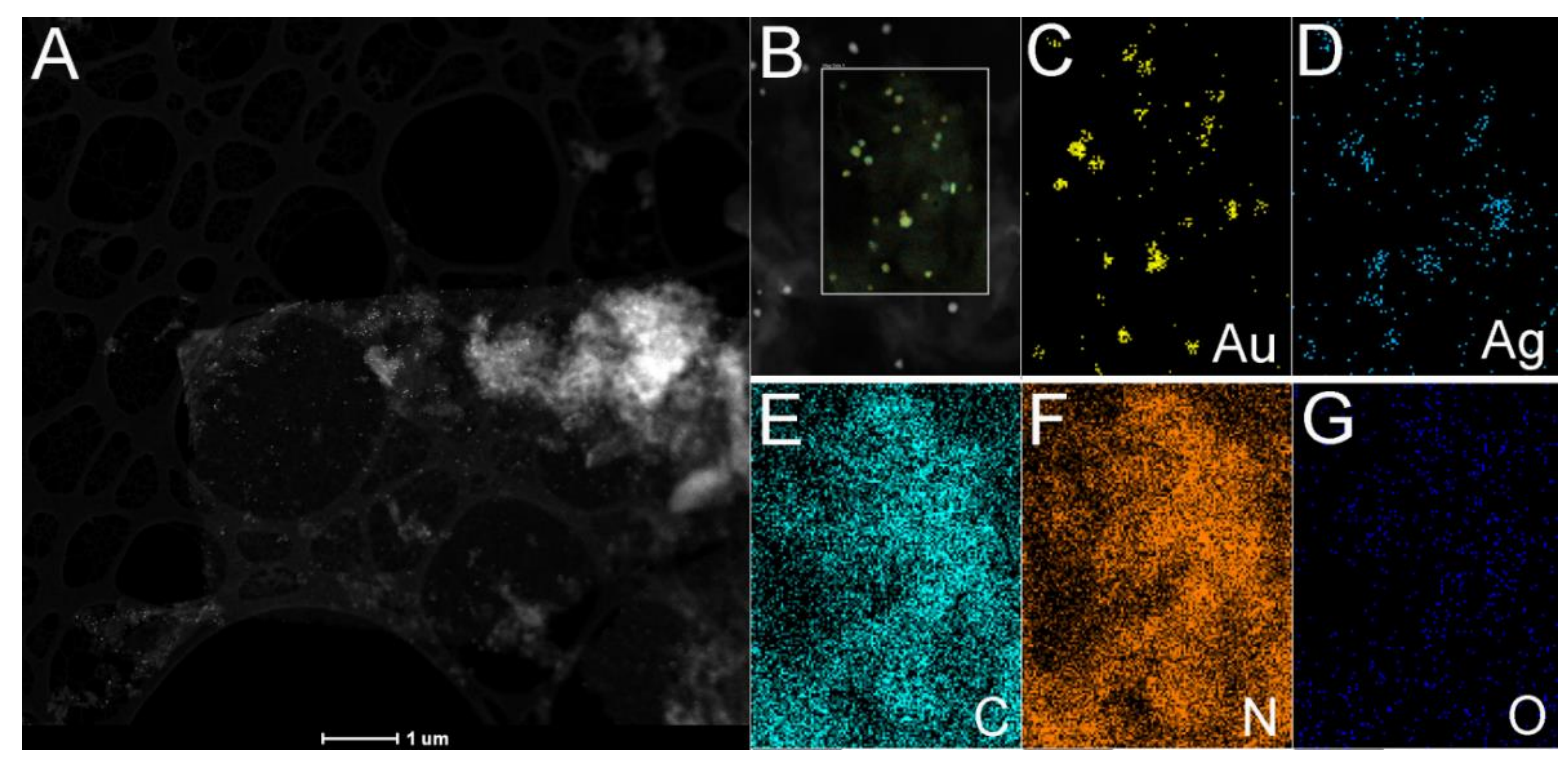

Figure 2. HAADF-STEM image of AuAg-g- $\mathrm{C}_{3} \mathrm{~N}_{4}$ nanohybrid 3 (A) displaying a $2 \mathrm{D}$ sheet of g- $\mathrm{C}_{3} \mathrm{~N}_{4}$ with metal nanoparticles grafted at the surface. EDS elemental mapping images for elements $\mathrm{Au}, \mathrm{Ag}, \mathrm{C}, \mathrm{N}$ and O: image (B) displays all elements mapping at a time, while images $(\mathbf{C}-\mathbf{G})$ display the individual elemental maps.

An even more detailed analysis is shown in Figures 3 and 4 and in Table S1 and Figures S3-S7 in Supplementary Materials. As it can be observed, the EDS mapped analysis of the composition of ca. $10 \mathrm{~nm}$ size Au-Ag NPs in Figure 3 indicates a main gold composition, whereas the same analysis for ca. $3 \mathrm{~nm}$ size $\mathrm{Au}-\mathrm{Ag} \mathrm{NP}$ indicates a main silver composition (Figure 4). This analysis has been repeated for several nanoparticles. The low oxygen concentration found around the small Ag-enriched nanoparticles rules out the formation of $\mathrm{Ag}_{2} \mathrm{O}$ or AgO NPs (see Supplementary Materials). Therefore, this analysis confirms the presence of bimetallic AuAg alloyed nanoparticles displaying two distinct sizes and compositions. The larger ca. $10 \mathrm{~nm}$ size NPs are gold-enriched, meanwhile the smaller $4 \mathrm{~nm}$ size NPs are silver enriched alloy NPs, respectively.

XPS analysis was carried out in order to gain insight into the surface elemental composition and the elemental chemical states of the atoms forming AuAg-g- $\mathrm{C}_{3} \mathrm{~N}_{4}$ nanohybrids 2-3 (see Figure 5 for $\mathbf{3}$ and Supplementary Materials for pristine g- $\mathrm{C}_{3} \mathrm{~N}_{4} \mathbf{1}$ and nanohybrid 2).
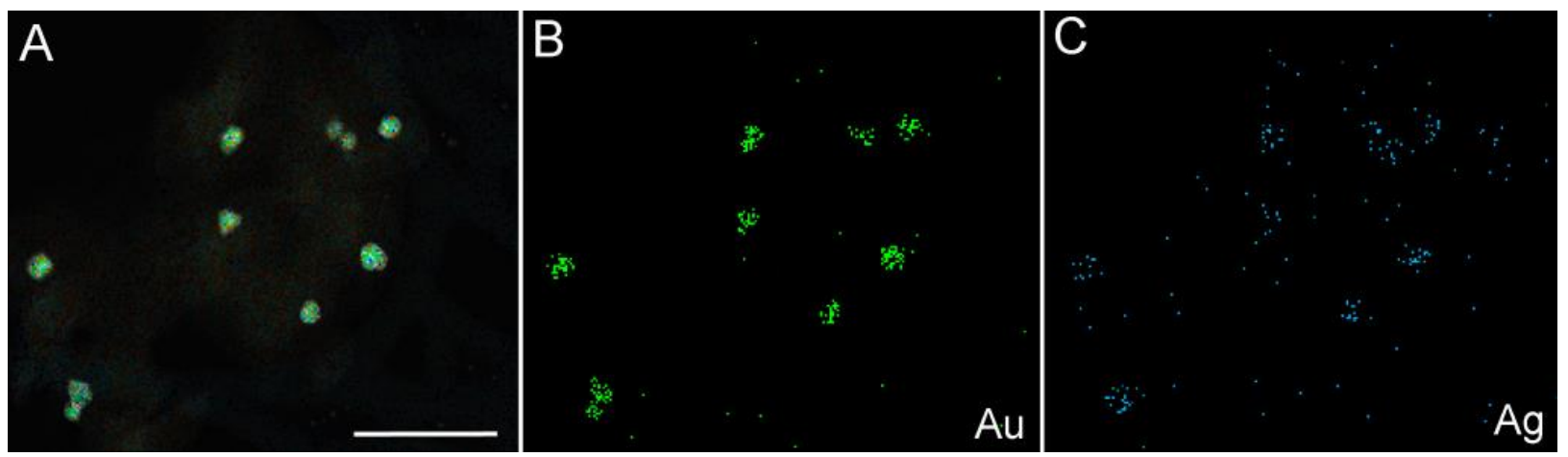

Figure 3. HAADF-STEM image of AuAg-g- $\mathrm{C}_{3} \mathrm{~N}_{4}$ nanohybrid 3 displaying $10 \mathrm{~nm}$ size metal nanoparticles. EDS elemental mapping images for elements $\mathrm{Au}$ and $\mathrm{Ag}$ : image (A) displays both elements mapping at a time, while images (B,C) display the individual Au and Ag elemental maps, respectively (bar corresponds to $100 \mathrm{~nm}$ ). 

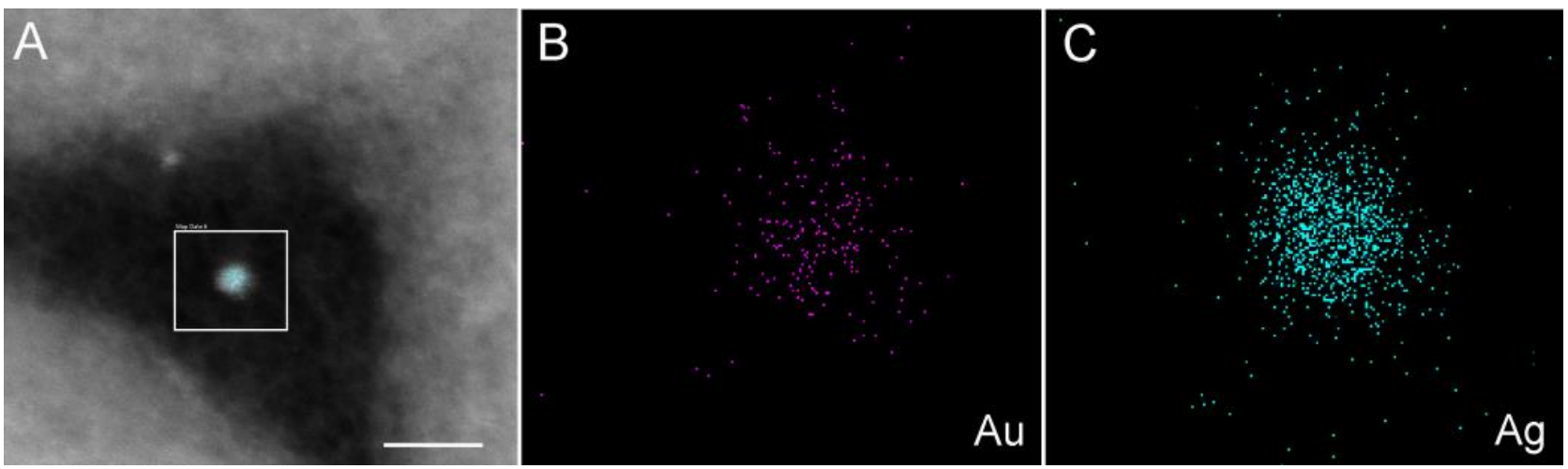

Figure 4. Detailed HAADF-STEM image of AuAg-g- $\mathrm{C}_{3} \mathrm{~N}_{4}$ nanohybrid 3 displaying a $4 \mathrm{~nm}$ size metal nanoparticle. EDS elemental mapping images for elements $\mathrm{Au}$ and Ag: image (A) displays both elements mapping at a time, while images $(\mathbf{B}, \mathbf{C})$ display the individual $\mathrm{Au}$ and Ag elemental maps, respectively (bar corresponds to $10 \mathrm{~nm}$ ).
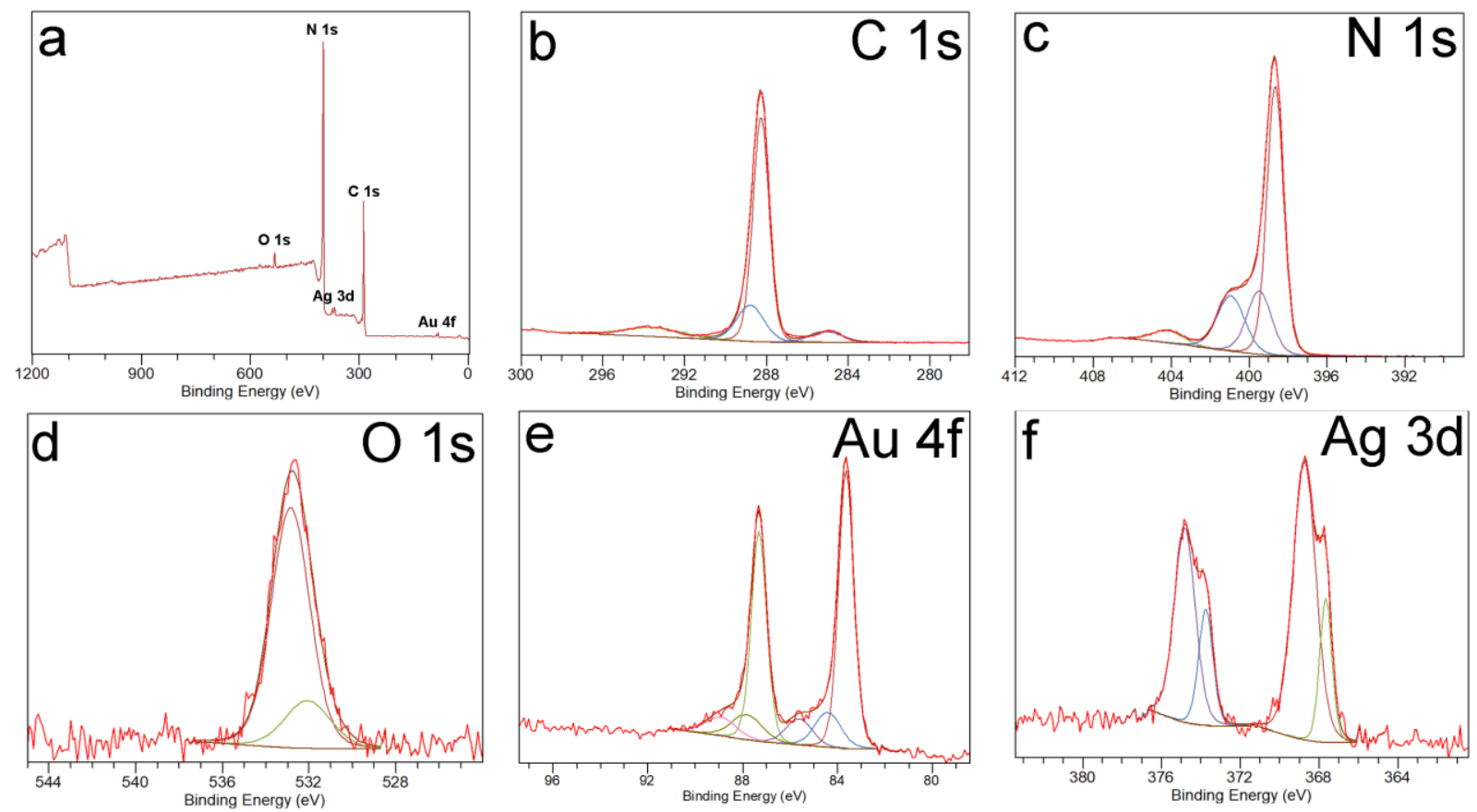

Figure 5. Wide XPS spectrum for AuAg-g- $\mathrm{C}_{3} \mathrm{~N}_{4} 3$ nanohybrid (a). High-resolution XPS spectra for C 1s (b), N 1s (c), $\mathrm{O} 1 \mathrm{~s}(\mathbf{d}), \mathrm{Au} 4 \mathrm{f}(\mathbf{e})$ and $\mathrm{Ag} 3 \mathrm{~d}(\mathbf{f})$.

The wide XPS spectra display the presence of intense peaks corresponding to $\mathrm{C}$ and $\mathrm{N}$, meanwhile small peaks assigned to $\mathrm{O}$, Au and Ag can also be detected. From the analysis of these wide spectra, it can be observed that the $\mathrm{wt}_{\mathrm{t}} \%$ composition of $\mathrm{Ag}$ and $\mathrm{Au}$ atoms is 0.9 and $0.9 \%$ (2) and 1.7 and $1.3 \%$ (3), respectively, pointing to some loss of $\mathrm{g}-\mathrm{C}_{3} \mathrm{~N}_{4}$ in the experimental workup, since a $0.5 \mathrm{wt} \%$ (2) or $1 \mathrm{wt} \%$ (3) of metals (gold + silver) was added in the preparation of nanohybrids 2 and 3 . It is also worth mentioning that the amount of oxygen (1.8 wt\% (2) or $2.3 \mathrm{wt} \%$ (3)) is larger than the one obtained for pristine $\mathrm{g}-\mathrm{C}_{3} \mathrm{~N}_{4} \mathbf{1}(0.78 \mathrm{wt} \%)$ pointing to an enrichment of oxygen species at the surface of this semiconductor, probably due to the synthetic thermal conditions in ethylene glycol. This result is similar to a previously reported one, in which the microwave treatment of g- $\mathrm{C}_{3} \mathrm{~N}_{4}$ in ethanol led to an increased density of oxygen-containing species (-OH groups) at the g- $\mathrm{C}_{3} \mathrm{~N}_{4}$ surface, conferring a higher hydrophilicity, better charge carrier separation and pollutant adsorbance [26]. In our case the presence of an increased amount of hydroxyl groups in AuAg-g- $\mathrm{C}_{3} \mathrm{~N}_{4}$ nanohybrids 2-3 would favor the charge carrier separation. 
Figure $5 b$ depicts the high-resolution XPS spectrum for the $C$ 1s region for nanohybrid 3, which is fitted into four peaks. The intense peak at $288.3 \mathrm{eV}$ is assigned to the $\mathrm{sp}^{2}$ carbon atoms in the triazine units of $\mathrm{g}-\mathrm{C}_{3} \mathrm{~N}_{4}(\mathrm{C}-\mathrm{N}=\mathrm{C})$, supported by the presence of the weak peak component of the $C 1$ s region at 293.6 assigned to double bond $\pi$-excitations. The peak at $288.8 \mathrm{eV}$ would be related to $\mathrm{C}-\mathrm{O}$ bonds, meanwhile the peak at 285.1 is associated to $\mathrm{C}-\mathrm{C}$ bonds $[27,28]$. In addition, Figure $5 \mathrm{c}$ provides the high-resolution spectrum of the $\mathrm{N}$ 1s region fitted again into four peaks. In a similar way, the intense peak at $398.6 \mathrm{eV}$ can be associated to $\mathrm{sp}^{2} \mathrm{~N}$ atoms in the triazine $(-\mathrm{C}-\mathrm{N}=\mathrm{C}-$ ) unit, again supported by the presence of a weak peak at $404.1 \mathrm{eV}$ arising from the double bond $\pi$-excitations. The $\mathrm{N}$ atoms between aromatic rings in the $\mathrm{C}_{3} \mathrm{~N}_{4}$ structure is assigned to the weak peak at $399.5 \mathrm{eV}$, whereas the presence of $\mathrm{NH}_{2}$ groups is related to the peak at $400.9 \mathrm{eV}[27,28]$. The assignment of the $\mathrm{C} 1 \mathrm{~s}$ and $\mathrm{N} 1 \mathrm{~s}$ regions for AuAg-g- $\mathrm{C}_{3} \mathrm{~N}_{4}$ nanohybrid 3 is very similar to the one obtained for pristine $g-\mathrm{C}_{3} \mathrm{~N}_{4} 1$ and nanohybrid 2 (see Supplementary Materials). On the other hand, the high-resolution XPS spectrum for the O 1s region (Figure $5 \mathrm{~d}$ ) displays a peak at $532.4 \mathrm{eV}$ fitted into two peaks attributed to the presence of hydroxyl groups at the semiconductor surface $(531.6 \mathrm{eV})$ and to adsorbed water molecules $(532.6 \mathrm{eV})$. The $\mathrm{O} 1 \mathrm{~s}$ peak value is similar to the peak obtained for a previously reported $\mathrm{Au}-\mathrm{g}-\mathrm{C}_{3} \mathrm{~N}_{4}$ nanohybrid at ca. $532 \mathrm{eV}$ [29] and also similar to the one obtained for pristine $\mathrm{g}-\mathrm{C}_{3} \mathrm{~N}_{4} \mathbf{1}$ and nanohybrid 2 (see Supplementary Materials).

The high-resolution XPS spectrum for the Au $4 \mathrm{f}$ region of 3 is shown in Figure 5e. The experimental signals are fitted to three spin-orbit doublets of different intensity, but equally separated in energy (ca. $3.7 \mathrm{eV}$ ). The most intense doublet at $83.6 \mathrm{eV}$ and $87.3 \mathrm{eV}$ can be assigned to metallic gold; the less intense doublets can be attributed to the presence of $\mathrm{Au}(\mathrm{I})$ and $\mathrm{Au}(\mathrm{III})$ oxidation states. The presence of gold atoms in positive oxidation states is attributed to a higher fraction of surface atoms with low coordination numbers when small size (sub-10 nm) nanoparticles are grafted on the carbon nitride surface [29,30]. In addition, the assignment of the $\mathrm{Au}(\mathrm{I})$ or $\mathrm{Au}(\mathrm{III})$ peaks to the organometallic precursor is ruled out since the presence of fluorine atom peaks arising from the pentafluorophenyl ligands are not observed.

Similarly, the high resolution XPS spectrum for the Ag 3d region of 3 displayed in Figure $5 \mathrm{f}$ shows two experimental signals, which are fitted to two spin-orbit doublets with a separation in energy of ca. $6.0 \mathrm{eV}$, characteristic of silver $3 \mathrm{~d}$ region. Taking into account the energy maxima of the doublet with peaks at 368.7 and $374.8 \mathrm{eV}$, we can assign this high intensity signals to metallic silver. The signals at 367.6 and 373.7 at slightly lower energy are related to the presence of $\mathrm{Ag}(\mathrm{I})$ due to the same reason as the one discussed for gold, i.e., the small size of silver NPs leads to a higher fraction of surface silver atoms with low coordination numbers [31].

The presence of Au-Ag NPs of different sizes and alloy compositions over $g-\mathrm{C}_{3} \mathrm{~N}_{4}$ provides an interesting material with a wide plasmonic absorption in the visible range arising from the variable metal composition of the grafted plasmonic nanoparticles. The objective pursued with the inclusion of Au-Ag NPs on carbon nitride nanosheets consists of enhancing the photocatalytic performance of this material under visible light. In this sense, the solid-state UV-vis analysis of AuAg-g- $\mathrm{C}_{3} \mathrm{~N}_{4}$ nanohybrids 2 and 3 provides interesting insights (see Figure 6). Thus, the inclusion of plasmonic Au-Ag NPs extends the visible light absorption from 400 to $600 \mathrm{~nm}$, through the appearance of the expected plasmonic absorption of the alloyed NPs. The plasmonic absorption arising from pure spherical Ag NPs in solution appears in the 400-420 nm range [32], whereas the plasmonic absorption arising from pure Au NPs in solution appears around 520-530 nm [12]. In the present case the two types of alloyed compositions found, i.e., silver and gold-enriched, permits to obtain a broad plasmonic absorption taking into account that the small size silver enriched NPs will absorb the higher energies of the visible light (ca. 400-420 nm) and the gold enriched ones will display a maximum around $520 \mathrm{~nm}$, absorbing intermediate energies of the visible light. Also, the heterojunction between the bimetallic NPs and $g-C_{3} N_{4}$ produces 
a slight decrease of the g- $\mathrm{C}_{3} \mathrm{~N}_{4}$ band gap from 2.74 to 2.71 (2) or $2.69 \mathrm{eV}$ (3) (see Tauc plots in Supplementary Materials).

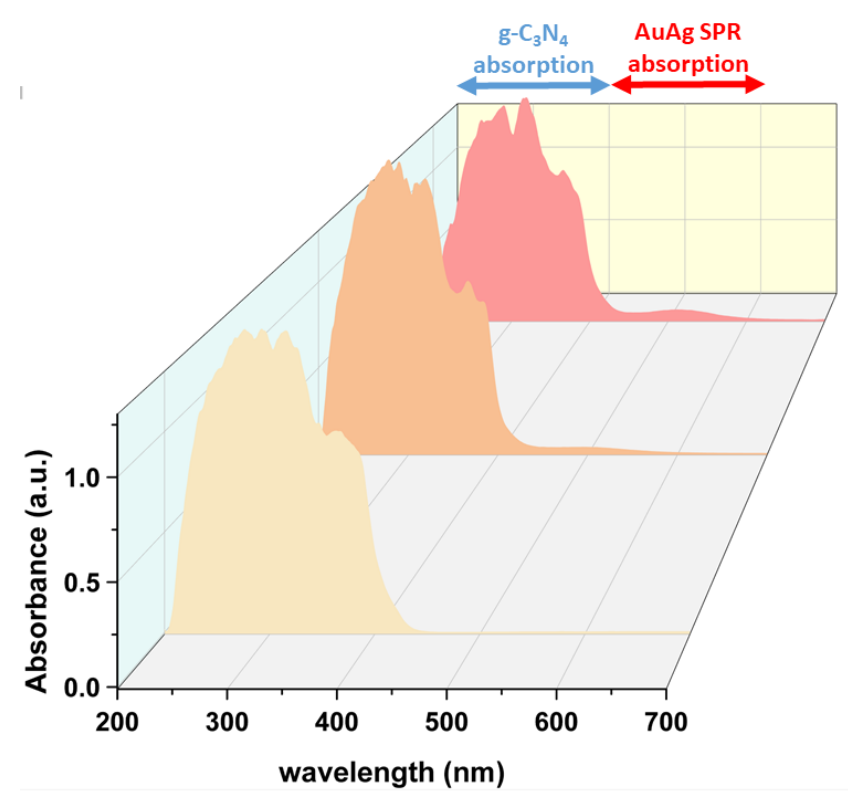

Figure 6. Solid UV-vis spectra for pristine g- $\mathrm{C}_{3} \mathrm{~N}_{4} \mathbf{1}$ (beige) and AuAg-g- $\mathrm{C}_{3} \mathrm{~N}_{4}$ nanohybrids 2 (orange) and 3 (red).

\subsection{Mechanism of Formation of Photocatalysts}

The use of organometallic compounds as precursors constitutes a very interesting approach for the synthesis of metallic nanostructures. In the case of pentafluorophenyl derivatives of gold (I) and/or silver (I), the reduction of metals under very mild reaction conditions has allowed the preparation of new types of nanostructures such as ultra-fine nanorods or nanowires [33], ultra-small gold nanoparticles [34] or gold colloidosomes [35]. There are usually two decomposition mechanisms for these compounds, i.e., bimolecular reductive elimination or deprotonation of acidic ligands by means of the basic pentafluorophenyl ligand. In the first case, the pentafluorophenyl ligands act as reducing agents by self-oxidizing to decafluorobiphenyl species, easily detectable in solution by ${ }^{19} \mathrm{~F}$ nuclear magnetic resonance. In the study of the behaviour of the $\left[\mathrm{Au}_{2} \mathrm{Ag}_{2}\left(\mathrm{C}_{6} \mathrm{~F}_{5}\right)_{4}\left(\mathrm{OEt}_{2}\right)_{2}\right]_{\mathrm{n}}$ precursor in the presence of $\mathrm{g}-\mathrm{C}_{3} \mathrm{~N}_{4}$ we have observed that the decomposition of the precursor occurs through the bimolecular reductive elimination mechanism (see Supplementary Materials). In addition, it is observed through ${ }^{19} \mathrm{~F}-\mathrm{NMR}$, that during the course of the decomposition reaction, the only fluorinated species that remains in solution is the anion $\left[\mathrm{Au}\left(\mathrm{C}_{6} \mathrm{~F}_{5}\right)_{2}\right]^{-}$, which indicates that in the reaction medium (ethyleneglycol) the organometallic precursor dissociates into its ionic components $\left[\mathrm{Au}\left(\mathrm{C}_{6} \mathrm{~F}_{5}\right)_{2}\right]^{-}$and $\left[\mathrm{Ag}\left(\mathrm{OEt}_{2}\right)\right]^{+}$, as expected when donor solvents are used (see Supplementary Materials).

Once the molecular mechanism of decomposition of the organometallic precursor is elucidated, the most striking result is the presence of two distinct populations of metal NPs in terms of size ( $2.4 \mathrm{~nm}$ vs. $5.0 \mathrm{~nm}$ in 2 or $3.0 \mathrm{~nm}$ vs. $9.8 \mathrm{~nm}$ in 3) and composition (silverenriched vs. gold-enriched). At this regard, the previous study by some of us of the decomposition of complex $\left[\mathrm{Au}_{2} \mathrm{Ag}_{2}\left(\mathrm{C}_{6} \mathrm{~F}_{5}\right)_{4}\left(\mathrm{OEt}_{2}\right)_{2}\right]_{\mathrm{n}}$ in the presence of hexadecylamine (HDA) showed the formation in solution of neutral $\left[\mathrm{M}\left(\mathrm{C}_{6} \mathrm{~F}_{5}\right)(\mathrm{HDA})\right](\mathrm{M}=\mathrm{Au}, \mathrm{Ag})$ species [22]. In addition, the decomposition of such intermediates displayed different reduction rates, allowing the control of the formation of AuAg alloyed nanoparticles with different metal compositions, depending on the experimental conditions. This type of species would also be formed at some points of the surface of $\mathrm{g}-\mathrm{C}_{3} \mathrm{~N}_{4}$ through the coordination of the $\left[\mathrm{M}\left(\mathrm{C}_{6} \mathrm{~F}_{5}\right)\right]$ units to the triazine moieties of $\mathrm{g}-\mathrm{C}_{3} \mathrm{~N}_{4}$ or, alternatively, $\mathrm{Ag}(\mathrm{I})$ centres would coordinate to $\mathrm{N}$-donor atoms of triazine units leading to ionic $[\mathrm{Ag}($ triazine $)]\left[\mathrm{Au}\left(\mathrm{C}_{6} \mathrm{~F}_{5}\right)_{2}\right]$ 
species acting as nucleation points for nanoparticle growth. Unfortunately nor the neutral neither the ionic species have been detected, although the equimolecular reaction between complex $\left[\mathrm{Au}_{2} \mathrm{Ag}_{2}\left(\mathrm{C}_{6} \mathrm{~F}_{5}\right)_{4}\left(\mathrm{OEt}_{2}\right)_{2}\right]_{\mathrm{n}}$ and triazine as ligand gives rise to the formation of the ionic species in solution (see Supplementary Materials), in contrast to the reactivity of HDA towards the same complex.

In any case, from the earlier studies we could anticipate that the $\mathrm{Ag}(\mathrm{I})$ intermediates are less stable and easier to reduce, leading to initial formation of Ag NPs. This observation was time-monitored through UV-vis absorption spectroscopy for HDA-capped AuAg alloyed NPs [22]. In the present study, we have collected the solid UV-vis spectrum at different reaction times for the process of formation of AuAg-g- $C_{3} N_{4}$ nanohybrid (3). Although the plasmon band shift in solid samples is not as evident as in solution, the solid UV-vis spectra display a slight red-shift of the plasmon absorption band with time in agreement with a sequential growth of plasmonic nanoparticles of different compositions (see Figure 7). Both the possible formation of distinct nucleation points of $\mathrm{Au}(\mathrm{I})$ and $\mathrm{Ag}(\mathrm{I})$ and the faster rate of formation of small $\mathrm{Ag}$ NPs at the surface of $\mathrm{g}-\mathrm{C}_{3} \mathrm{~N}_{4}$ would support the possibility of a separate growth of two distinct types of metal nanoparticles. Based on the analysis of this mechanism a further control of the reaction conditions, specially using lower temperatures, would provide the possibility of obtaining composition-controlled populations of Au-Ag NPs on $g-C_{3} N_{4}$ surfaces mostly enriched with one of the metals.

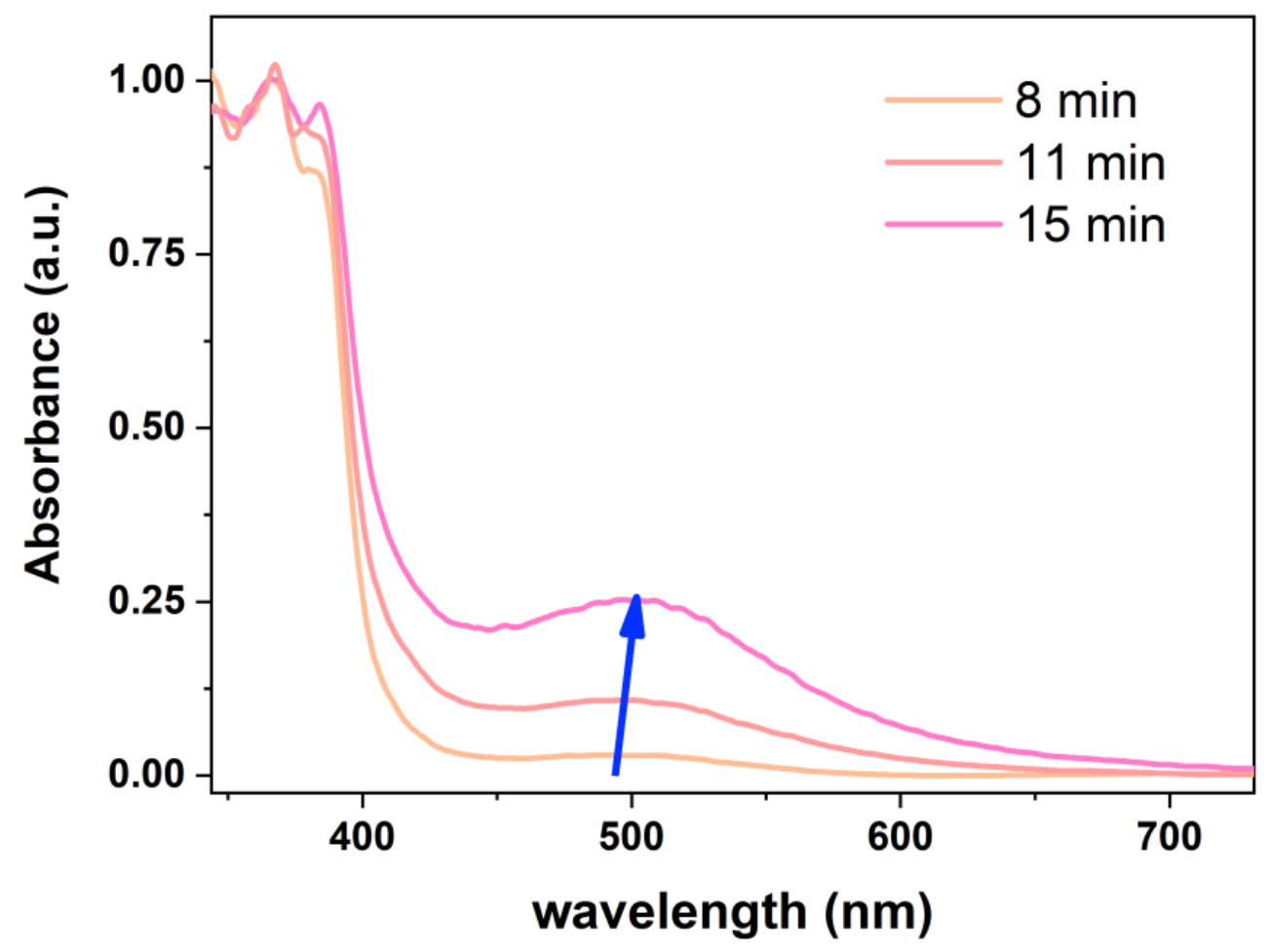

Figure 7. Time-monitored solid UV-vis spectra displaying the plasmonic absorption in the formation process of AuAg-g- $\mathrm{C}_{3} \mathrm{~N}_{4}$ nanohybrid (3). The blue arrow indicates a slight red-shift of the plasmonic absorption with time.

\subsection{Photodegradation of Ibuprofen}

The synthesis of AuAg-g- $\mathrm{C}_{3} \mathrm{~N}_{4}$ nanohybrids displaying broad plasmonic absorptions thanks to the formation of two types of plasmonic NPs at the surface of $g-C_{3} \mathrm{~N}_{4}$, prompted us to study their photocatalytic behavior under visible light towards the degradation of ibuprofen.

Figure 8 compares the photocatalytic degradation of ibuprofen using pristine $g-\mathrm{C}_{3} \mathrm{~N}_{4}$ or AuAg-g- $\mathrm{C}_{3} \mathrm{~N}_{4}$ nanohybrids 2 and 3 under low power visible LED light source. Pristine g- $\mathrm{C}_{3} \mathrm{~N}_{4} \mathbf{1}$ and nanohybrid 3 were also tested using sunlight. The corresponding blank experiments (photolysis) are also included in Figure 8. The photolysis depletion of ibuprofen 
with both sources of light was negligible, which illustrates the low photodegradability and persistence of ibuprofen in water. The degradation rates observed in the experiments performed under sunlight were faster than under LED light. The ibuprofen sample was completely removed within 120 min under sunlight, whereas around $5 \%$ of ibuprofen remained in solution after $360 \mathrm{~min}$ when the mixtures were irradiated with LED light. On the other hand, when the catalyst employed in the degradations contained nanoparticles of noble metals (gold and silver), the pseudo-first-kinetic constants obtained were larger than with g- $\mathrm{C}_{3} \mathrm{~N}_{4}$. The kinetic constants obtained in the photodegradations with g- $\mathrm{C}_{3} \mathrm{~N}_{4}$ and AuAg-g- $\mathrm{C}_{3} \mathrm{~N}_{4}$ nanohybrid 3 under sunlight were 0.027 and $0.036 \mathrm{~min}^{-1} ; \mathrm{g}-\mathrm{C}_{3} \mathrm{~N}_{4}$, $\mathrm{AuAg}-\mathrm{g}-\mathrm{C}_{3} \mathrm{~N}_{4}$ nanohybrid 2 and AuAg-g- $\mathrm{C}_{3} \mathrm{~N}_{4}$ nanohybrid 3 under visible LED light were $0.0086,0.012$ and $0.012 \mathrm{~min}^{-1}$, respectively (see Supplementary Materials).

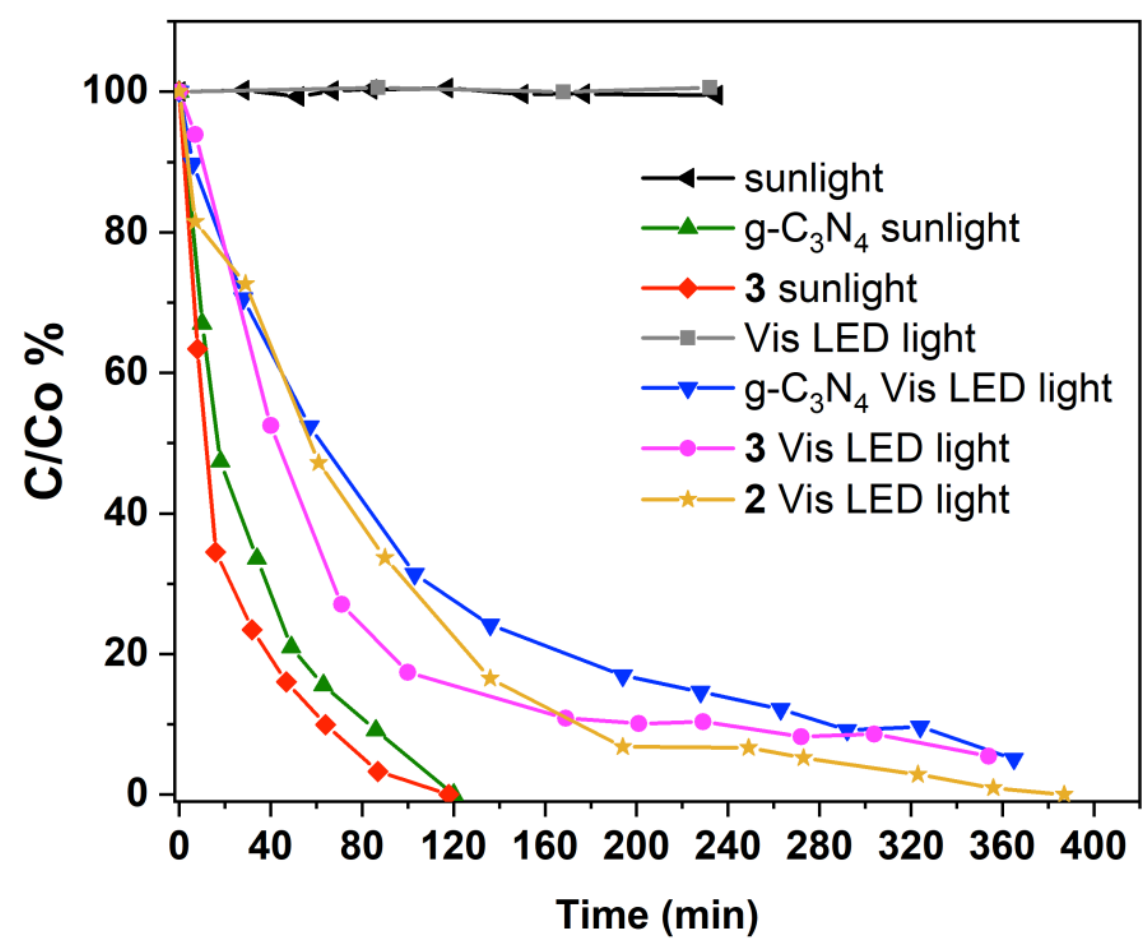

Figure 8. Evolution of ibuprofen concentration during its degradation with $\mathrm{g}-\mathrm{C}_{3} \mathrm{~N}_{4}$ and nanohybrids 2 and 3 , under visible LED light or under sunlight.

The presence of two types of metal nanoparticles leading to a broad plasmonic absorption in nanohybrids $\mathbf{2}$ and $\mathbf{3}$ clearly improved the efficiency of the photodegradations with respect to g- $\mathrm{C}_{3} \mathrm{~N}_{4}$. In general, the formation of metal-semiconductor heterojunctions through the grafting of metal NPs at the surface of a semiconductor would increase the photocatalytic efficiency through several paths: (i) the metal NP may act as co-catalyst; (ii) the metal NPs can improve the electron-hole separation acting as electron sinks thanks to the formation of a Schottky barrier between the metal and the semiconductor; and (iii) when the metal NPs display plasmonic properties, the localized surface plasmon resonance (LSPR) induces additional local temperature increase (improves exciton formation in the semiconductor), optical near field enhancement (transfer of photons to the semiconductor) and hot-electron injection from the plasmonic nanoparticle to the conduction band of the semiconductor, preventing a fast electron-hole recombination $[10,11,19]$.

An indirect proof of the improved charge separation is the analysis of the photoluminescent (PL) properties of $\mathrm{g}-\mathrm{C}_{3} \mathrm{~N}_{4}$ based materials. Figure 9 depicts the emission spectrum of pristine g- $\mathrm{C}_{3} \mathrm{~N}_{4}$ with a maximum at $440 \mathrm{~nm}$ (excitation at $350 \mathrm{~nm}$ ). This emission band arises from interband recombination of the photogenerated electron-hole pairs being the energy of the emission the one corresponding to the semiconductor band-gap. The formation of plasmonic AuAg NPs of two distinct populations of Ag-enriched and Au-enriched 
compositions at the surface of $\mathrm{g}-\mathrm{C}_{3} \mathrm{~N}_{4}$ provokes a drastic quenching of the photoemissive properties of nanohybrids 2 and 3 , suggesting a greatly improved and efficient electronhole separation for these systems. This result would be in agreement with an effective electron-trapping effect by the Au-Ag NPs arising from the formation of the Schottky barrier, i.e., heterojunction effect, although favorable LSPR effects may also contribute to the improved photocatalytic properties.

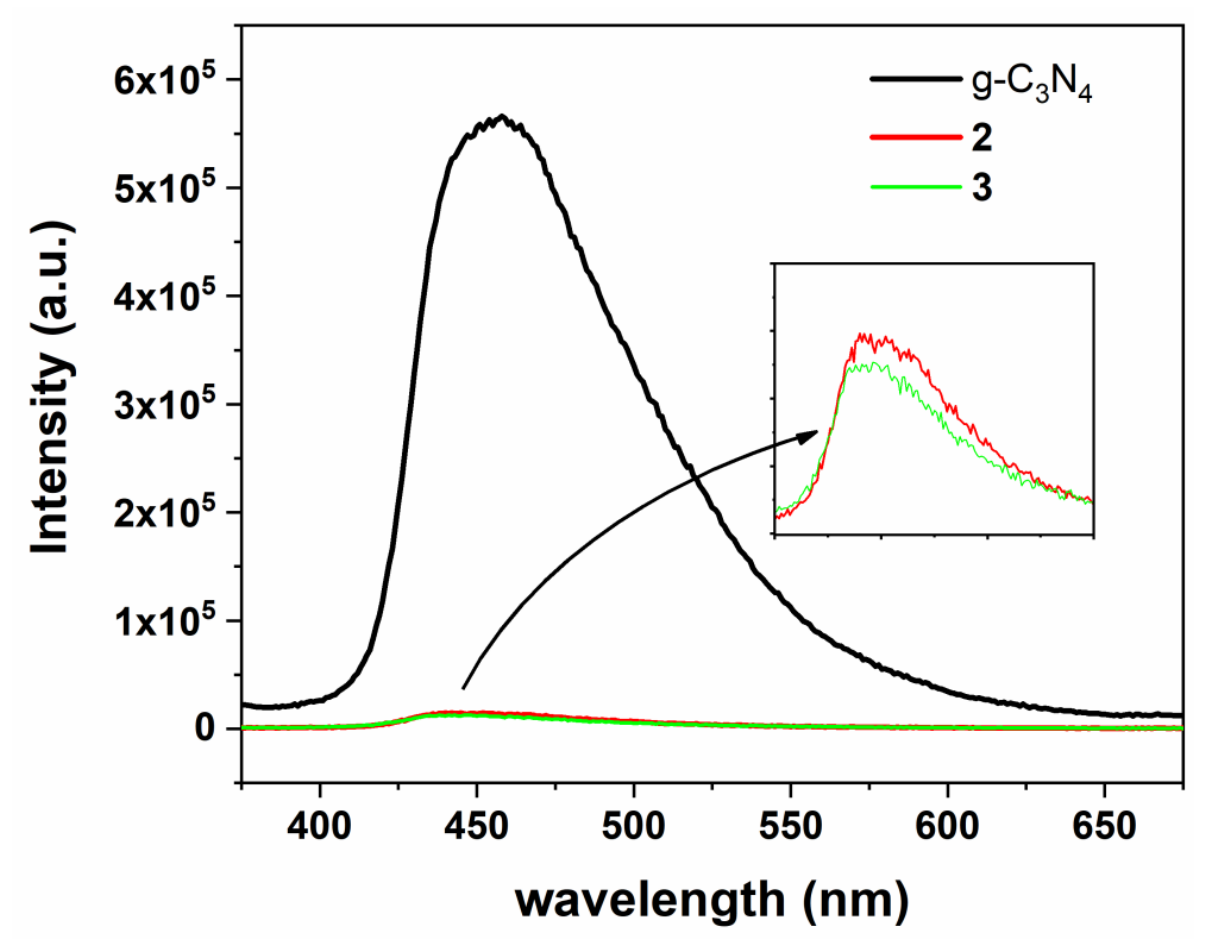

Figure 9. Photoluminescent spectra of $\mathrm{g}-\mathrm{C}_{3} \mathrm{~N}_{4}$ and nanohybrids 2 and 3 in solid state (excitation wavelength is $350 \mathrm{~nm}$ ).

In order to elucidate the mechanism of degradation of ibuprofen, quenching experiments for the detection of reactive oxygen species were performed. During the photocatalytic degradation process, many reactive oxygen species responsible for pollutants' depletion can be generated. To evaluate which species played a main role in the degradation process of ibuprofen under visible light, catalyzed by AuAg-g- $C_{3} N_{4}$ nanohybrid 3 and irradiation, three trapping experiments were carried out. tert-Butanol was used as scavenger for hydroxyl radicals $(\cdot \mathrm{OH})$. Triethanolamine was employed as scavenger for photogenerated holes $\left(\mathrm{h}^{+}\right)$. In addition, to study the influence of superoxide radicals $\left(\cdot \mathrm{O}_{2}{ }^{-}\right)$, the degradation was performed under inert $\mathrm{N}_{2}$ atmosphere to quench them [36-39]. As can be seen in Figure 10, triethanolamine completely quenched the ibuprofen degradation and when the reaction was evaluated under $\mathrm{N}_{2}$ atmosphere the degradation rate was also greatly quenched. In contrast, tert-butanol had a slight effect on the photodegradation. According to these results, the holes $\left(\mathrm{h}^{+}\right)$and superoxide radicals $\left(\cdot \mathrm{O}_{2}{ }^{-}\right)$are the main species involved in the photocatalysis, whereas the hydroxyl radicals $(\cdot \mathrm{OH})$ play a minor role in the photocatalytic mechanism. Taking into account scavenger effects, it is likely that under visible light irradiation both heterojunction effects and LSPR effects play an important role. On the one hand, the drastic charge carrier separation found for nanohybrids $\mathbf{2}$ and $\mathbf{3}$ agrees with a migration of photogenerated electrons in the g- $\mathrm{C}_{3} \mathrm{~N}_{4}$ semiconductor towards $\mathrm{Au}-\mathrm{Ag}$ NPs. In addition, LSPR effects such as localized heating or near-field enhancement would also assist the charge carrier separation at the semiconductor. The transfer of plasmonic hot electrons from Ag-enriched and Au-enriched NPs to the $\mathrm{CB}$ g- $\mathrm{C}_{3} \mathrm{~N}_{4}$ would also provide a charge carrier separation at the plasmonic NPs. In any case, the obtained charge carrier separation greatly favors the formation of the superoxide radicals $\left(\cdot \mathrm{O}_{2}{ }^{-}\right)$through 
the reduction of oxygen thanks to the photogenerated electrons at the $\mathrm{CB}$ of $\mathrm{g}-\mathrm{C}_{3} \mathrm{~N}_{4}$ or $\mathrm{Au}-\mathrm{Ag}$ NPs. Indeed, according to previous reports [40,41], the CB edge of $\mathrm{g}-\mathrm{C}_{3} \mathrm{~N}_{4}$ is more negative $\left(-1.19 \mathrm{eV}\right.$, vs. NHE) than the $\mathrm{O}_{2} / \cdot \mathrm{O}_{2}{ }^{-}$potential $(-0.33 \mathrm{eV}$, vs. NHE). At the same time, holes $\left(\mathrm{h}^{+}\right)$are formed at the plasmonic NPs and at the VB of g- $\mathrm{C}_{3} \mathrm{~N}_{4}$. Therefore, in addition to the superoxide radicals $\left(\cdot \mathrm{O}_{2}{ }^{-}\right)$the holes $\left(\mathrm{h}^{+}\right)$generated also participate in the degradation of ibuprofen, in agreement with the experimental findings (see Figure 11).

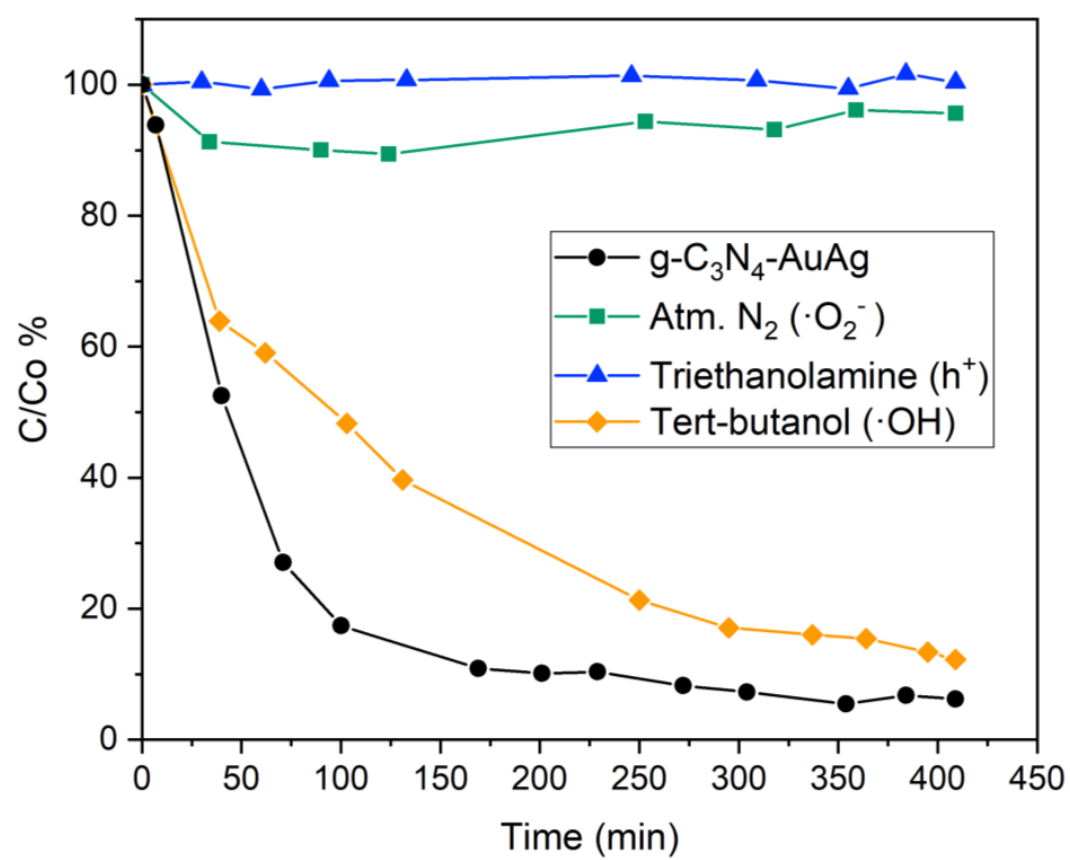

Figure 10. Evolution of ibuprofen concentration during photocatalytic degradation with 3 under visible light irradiation and effect of scavengers.

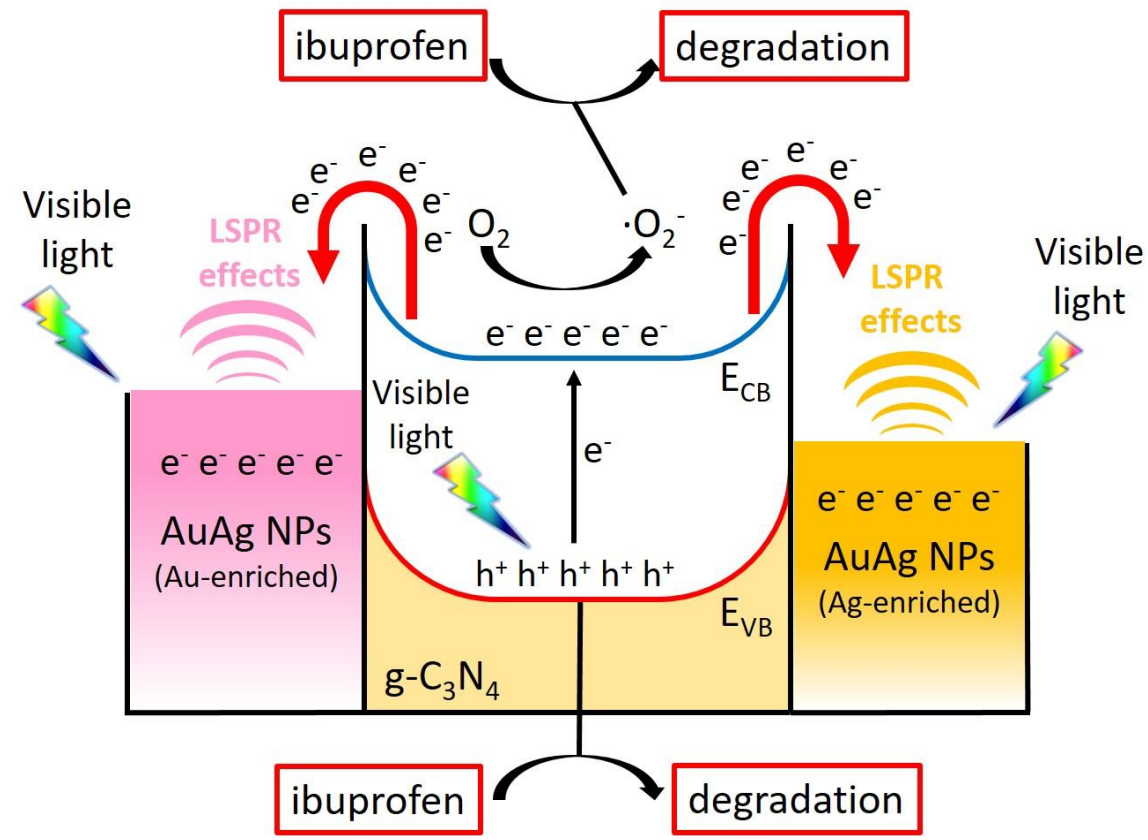

Figure 11. Schematic representation of the mechanism of degradation of ibuprofen through the plasmonic hot-electron injection from Au-enriched and Ag-enriched NPs and from electronic excitation of $\mathrm{g}-\mathrm{C}_{3} \mathrm{~N}_{4}$ semiconductor. 
The secondary role played by hydroxyl radicals is in agreement with the unfavourable potential of the $\mathrm{g}-\mathrm{C}_{3} \mathrm{~N}_{4} \mathrm{VB}(1.65 \mathrm{eV}$, vs. NHE) for the formation of the $\mathrm{OH}$ radicals from $\mathrm{OH}^{-}$groups $\left(\mathrm{OH} / \mathrm{OH}^{-}\right.$potential is $2.38 \mathrm{eV}$, vs. $\left.\mathrm{NHE}\right)$ or from $\mathrm{H}_{2} \mathrm{O}\left(\mathrm{OH} / \mathrm{H}_{2} \mathrm{O}\right.$ potential is $2.72 \mathrm{eV}$, vs. $\mathrm{NHE}$ ). In this case, the $\cdot \mathrm{OH}$ radical species might be formed in an indirect manner from $\mathrm{H}_{2} \mathrm{O}_{2}$, because of the following reduction pathway [42]:

$\mathrm{g}-\mathrm{C}_{3} \mathrm{~N}_{4}\left(\mathrm{e}^{-}\right)+\mathrm{O}_{2} \rightarrow \cdot \mathrm{O}_{2}^{-}$

$\mathrm{g}^{-} \mathrm{C}_{3} \mathrm{~N}_{4}\left(\mathrm{e}^{-}\right)+\cdot \mathrm{O}_{2}^{-}+2 \mathrm{H}^{+} \rightarrow \mathrm{H}_{2} \mathrm{O}_{2}$

$\mathrm{g}_{-} \mathrm{C}_{3} \mathrm{~N}_{4}\left(\mathrm{e}^{-}\right)+\mathrm{H}_{2} \mathrm{O}_{2} \rightarrow \cdot \mathrm{OH}+\mathrm{OH}^{-}$

Finally, the mechanism of degradation of ibuprofen under sunlight would be similar since both the hot-electron injection in the $\mathrm{CB}$ of $\mathrm{g}-\mathrm{C}_{3} \mathrm{~N}_{4}$ and the electronic excitation from the $\mathrm{VB}$ to the $\mathrm{CB}$ of the $\mathrm{g}-\mathrm{C}_{3} \mathrm{~N}_{4}$ semiconductor could be reached. The larger irradiance of the sunlight with respect to visible LED light would be responsible for the faster kinetics of the processes involved thanks to the heterojunction and LSPR effects.

\section{Conclusions}

We have developed a facile approach for the synthesis of $\mathrm{Au}-\mathrm{Ag} / \mathrm{g}-\mathrm{C}_{3} \mathrm{~N}_{4}$ nanohybrids with enhanced photocatalytic activity in degradation of ibuprofen under white LED light and under sunlight. The in-depth analysis of the nanohybrids composition points to the formation of two types of alloyed Au-Ag NPs differing in terms of size and composition in a single synthetic step. Thus, small size Ag-enriched NPs and larger size Au-enriched NPs provide a broad plasmonic absorption in the visible that, together with heterojunction effects greatly preclude the electron-hole recombination at the semiconductor. This improved charge-carrier separation enhances the photocatalytic efficiency of the nanohybrid photocatalysts towards the degradation of ibuprofen, which is a persistent drug in water. Quenching experiments have provided the information for proposing a mechanism of photodegradation of ibuprofen using $\mathrm{Au}-\mathrm{Ag} / \mathrm{g}-\mathrm{C}_{3} \mathrm{~N}_{4}$ nanohybrid as photocatalyst. Superoxide radicals and holes are the main active species involved in the degradation process. More studies based on the use of real polluted water samples and up-scaling of the photocatalytic process are underway.

Supplementary Materials: The following are available online at https:/ / www.mdpi.com/article/10.3 390/ma14143912/s1, Figure S1. Size histograms of Ag-enricbed AuAg NPs (left) and Au-enriched AuAg-NPs (right) on nanohybrid 2, Figure S2. Size histograms of Ag-enricbed AuAg NPs (left) and Au-enriched AuAg-NPs (right) on nanohybrid 3, Figure S3. HAADF-STEM images of AuAgg- $\mathrm{C}_{3} \mathrm{~N}_{4}$ nanohybrid 3 (A-B) displaying Au-enriched AuAg nanoparticles grafted on the surface of g- $\mathrm{C}_{3} \mathrm{~N}_{4}$ and EDS individual elemental mappings for elements $\mathrm{Au}, \mathrm{Ag}, \mathrm{C}, \mathrm{N}$ and $\mathrm{O}$. Note that the HAADF-STEM images A-B display all elements mapping at a time, Figure S4. EDS spectra of selected Au-enriched Au-Ag NPs of ca. 10 nm size (NPs 1 and 2 in Table S1), Figure S5. EDS spectra of selected Ag-enriched Au-Ag NPs of ca. 5 nm size. (NPs 3-5 in Table S1), Figure S6. EDS spectra of selected Ag-enriched Au-Ag NPs of ca. 5 nm size. (NPs 6-10 in Table S1), Figure S7. EDS spectra of selected Ag-enriched Au-Ag NPs of ca. 5 nm size. (NPs 11-17 in Table S1), Figure S8. HAADF-STEM images of AuAg-g- $\mathrm{C}_{3} \mathrm{~N}_{4}$ nanohybrid 3 (A-D) displaying Ag-enriched AuAg nanoparticles of ca. $5 \mathrm{~nm}$ size grafted on the surface of $\mathrm{g}-\mathrm{C}_{3} \mathrm{~N}_{4}$ and EDS individual elemental mappings for elements $\mathrm{Au}, \mathrm{Ag}$ and O. Note that the HAADF-STEM images A-D display all elements mapping at a time. The analysis of the oxygen content discards the presence of $\mathrm{Ag}_{2} \mathrm{O}$ species (bars correspond to $10 \mathrm{~nm}$ ), Figure S9. Wide XPS spectrum for pristine $\mathrm{g}-\mathrm{C}_{3} \mathrm{~N}_{4}$ (a). High-resolution XPS spectra for O 1s (b) C 1s (c), N $1 \mathrm{~s}(\mathrm{~d})$, Figure S10. Wide XPS spectrum for AuAg- $\mathrm{g}-\mathrm{C}_{3} \mathrm{~N}_{4}$ nanohybrid 2 (a). High-resolution XPS spectra for C 1s (b) N 1s (c), O 1s (d), Au 4f (e), Ag 3d (f), Figure S11. Tauc plots for 1-3, Figure S12. ${ }^{19} \mathrm{~F}$ NMR spectrum of the in situ formation of AuAg-g- $\mathrm{C}_{3} \mathrm{~N}_{4}$ nanohybrid 3. The obtained profile is assigned to the presence in solution of the molecule $\mathrm{C}_{6} \mathrm{~F}_{5}-\mathrm{C}_{6} \mathrm{~F}_{5}$ as a byproduct of the reduction of $\mathrm{Au}(\mathrm{I})$ and $\mathrm{Ag}(\mathrm{I})$ ions to the zeroth oxidation state., Figure S13. ${ }^{19} \mathrm{~F}$ NMR spectrum of the reaction mixture of complex $\left[\mathrm{Au}_{2} \mathrm{Ag}_{2}\left(\mathrm{C}_{6} \mathrm{~F}_{5}\right)_{4}\left(\mathrm{OEt}_{2}\right)_{2}\right]_{\mathrm{n}}$ and $\mathrm{g}-\mathrm{C}_{3} \mathrm{~N}_{4}$. The presence of broad signals assigned to $\left[\mathrm{Au}\left(\mathrm{C}_{6} \mathrm{~F}_{5}\right)_{2}\right]^{-}$units in solution agrees with the dissociation of the precursor into its ionic components $\left[\mathrm{Au}\left(\mathrm{C}_{6} \mathrm{~F}_{5}\right)_{2}\right]^{-}$and $\left[\mathrm{Ag}\left(\mathrm{OEt}_{2}\right)\right]^{+}$, as expected when a donor solvent such as ethyleneglycol is used, Figure S14. ${ }^{19} \mathrm{~F}$ NMR spectrum of the in situ reaction between complex $\left[\mathrm{Au}_{2} \mathrm{Ag}_{2}\left(\mathrm{C}_{6} \mathrm{~F}_{5}\right)_{4}\left(\mathrm{OEt}_{2}\right)_{2}\right]_{\mathrm{n}}$ in the presence of melamine in a 4:2 metals:melamine ratio. The obtained profile is assigned to the 
presence of $\left[\mathrm{Au}\left(\mathrm{C}_{6} \mathrm{~F}_{5}\right)_{2}\right]^{-}$units in solution, in agreement with the coordination of silver to melamine, Figure S15. Kinetics of the photocatalysts 1 (left), 2 (center) and 3 (right) under visible light. The fitting results are represented assuming a pseudo-first order reaction, Figure S16. Kinetics of the photocatalysts 1 (left), and 3 (right) under sunlight. The fitting results are represented assuming a pseudo-first order reaction. Table S1. EDS analysis of AuAg NPs on nanohybrid 3 showing the wt $\%$ composition of $\mathrm{Au}, \mathrm{Ag}$ and $\mathrm{O}$.

Author Contributions: Conceptualization, M.M. and M.T.T.; methodology, M.J.-S.; investigation, M.J.-S.; resources, M.M.; writing-original draft preparation, M.J.-S.; writing-review and editing, M.M. and M.T.T.; visualization, M.J.-S.; supervision, M.M. and M.T.T.; project administration, M.M.; funding acquisition, M.M. All authors have read and agreed to the published version of the manuscript.

Funding: This research was funded by D.G.I. MINECO/FEDER (project number PID2019-104379RBC22 (AEI/FEDER, UE)) and the EC through the FEDER POCTEFA project NUTRIA (EFA 356/19). M. Jiménez-Salcedo is funded through the Universidad de La Rioja for a FPI grant.

Institutional Review Board Statement: Not applicable.

Informed Consent Statement: Not applicable.

Data Availability Statement: Data sharing is not applicable.

Acknowledgments: We thank the SERMET-Universidad de Cantabria. The authors also acknowledge the use of instrumentation as well as the technical advice provided by the National Facility ELECMI ICTS, node "Laboratorio de Microscopias Avanzadas" at Universidad de Zaragoza.

Conflicts of Interest: The authors declare no conflict of interest.

\section{References}

1. Boukherroub, R.; Ogale, S.B.; Robertson, N. Nanostructured Photocatalyst. From Materials to Applications in Solar Fuels and Environmental Remediation; Boukherroub, R., Ogale, S.B., Robertson, N., Eds.; Elsevier: Amsterdam, The Netherlands, 2020.

2. Dionysiou, D.D.; Puma, G.L.; Ye, J.; Schneider, J.; Bahnemann, D. Photocatalysis: Applications; Dionysiou, D.D., Puma, G.L., Ye, J., Schneider, J., Bahnemann, D., Eds.; Royal Society of Chemistry: Cambridge, UK, 2016.

3. Schneider, J.; Matsuoka, M.; Takeuchi, M.; Zhang, J.; Horiuchi, Y.; Anpo, M.; Bahnemann, D.W. Understanding TiO 2 Photocatalysis: Mechanisms and Materials. Chem. Rev. 2014, 114, 9919-9986. [CrossRef]

4. Khan, M.M.; Pradhan, D.; Sohn, Y. Nanocomposites for Visible Light-induced Photocatalysis; Khan, M.M., Pradhan, D., Sohn, Y., Eds.; Springer: Cham, Switzerland, 2017.

5. Ghosh, S. Visible-Light-Active Photocatalysis: Nanostructured Catalyst Design, Mechanisms, and Applications; Ghosh, S., Ed.; WileyVCH: Weinheim, Germany, 2018.

6. Marcelino, R.B.P.; Amorim, C.C. Towards visible-light photocatalysis for environmental applications: Band-gap engineering versus photons absorption-A review. Environ. Sci. Pollut. Res. 2019, 26, 4155-4170. [CrossRef] [PubMed]

7. Peiris, S.; McMurtrie, J.; Zhu, H.-Y. Metal nanoparticle photocatalysts: Emerging processes for green organic synthesis. Catal. Sci. Technol. 2016, 6, 320-338. [CrossRef]

8. Tong, H.; Ouyang, S.; Bi, Y.; Umezawa, N.; Oshikiri, M.; Ye, J. Nano-photocatalytic Materials: Possibilities and Challenges. Adv. Mater. 2012, 24, 229-251. [CrossRef]

9. Ong, W.-J.; Tan, L.-L.; Ng, Y.H.; Yong, S.-T.; Chai, S.-P. Graphitic Carbon Nitride $\left(\mathrm{g}_{-} \mathrm{C}_{3} \mathrm{~N}_{4}\right)$-Based Photocatalysts for Artificial Photosynthesis and Environmental Remediation: Are We a Step Closer To Achieving Sustainability? Chem. Rev. 2016, 116, 7159-7329. [CrossRef]

10. Teixeira, I.F.; Barbosa, E.C.M.; Tsang, S.C.E.; Camargo, P.H.C. Carbon nitrides and metal nanoparticles: From controlled synthesis to design principles for improved photocatalysis. Chem. Soc. Rev. 2018, 47, 7783-7817. [CrossRef] [PubMed]

11. Kavitha, R.; Nithya, P.M.; Girish Kumar, S. Noble metal deposited graphitic carbon nitride based heterojunction photocatalysts. App. Surf. Sci. 2020, 508, 145142. [CrossRef]

12. Liz-Marzán, L.M. Tailoring Surface Plasmons through the Morphology and Assembly of Metal Nanoparticles. Langmuir 2005, 22, 32-41. [CrossRef]

13. Noguez, C. Surface Plasmons on Metal Nanoparticles: The Influence of Shape and Physical Environment. J. Phys. Chem. C 2007, 111, 3806-3819. [CrossRef]

14. Polavarapu, L.; Perez-Juste, J.; Xu, Q.-H.; Liz-Marzan, L.M. Optical sensing of biological, chemical and ionic species through aggregation of plasmonic nanoparticles. J. Mater. Chem. C 2014, 2, 7460-7476. [CrossRef]

15. Guan, Z.; Polavarapu, L.; Xu, Q.-H. Enhanced Two-Photon Emission in Coupled Metal Nanoparticles Induced by Conjugated Polymers. Langmuir 2010, 26, 18020-18023. [CrossRef] 
16. Kelly, K.L.; Coronado, E.; Zhao, L.L.; Schatz, G.C. The Optical Properties of Metal Nanoparticles: The Influence of Size, Shape, and Dielectric Environment. J. Phys. Chem. B 2002, 107, 668-677. [CrossRef]

17. Rycenga, M.; Cobley, C.M.; Zeng, J.; Li, W.; Moran, C.H.; Zhang, Q.; Qin, D.; Xia, Y. Controlling the Synthesis and Assembly of Silver Nanostructures for Plasmonic Applications. Chem. Rev. 2011, 111, 3669-3712. [CrossRef]

18. Chou, C.-H.; Chen, F.-C. Plasmonic nanostructures for light trapping in organic photovoltaic devices. Nanoscale 2014, 6, 8444-8458. [CrossRef] [PubMed]

19. Zhou, N.; Lopez-Puente, V.; Wang, Q.; Polavarapu, L.; Pastoriza-Santos, I.; Xu, Q.-H. Plasmon-enhanced light harvesting: Applications in enhanced photocatalysis, photodynamic therapy and photovoltaics. RSC Adv. 2015, 5, 29076-29097. [CrossRef]

20. Baffou, G.; Quidant, R. Nanoplasmonics for chemistry. Chem. Soc. Rev. 2014, 43, 3898-3907. [CrossRef] [PubMed]

21. $\mathrm{Fu}, \mathrm{J} . ; \mathrm{Yu}, \mathrm{J} . ;$ Jiang, C.; Cheng, B. g- $\mathrm{C}_{3} \mathrm{~N}_{4}$-Based Heterostructured Photocatalysts. Adv. Energy Mater. 2018, 8, 1701503. [CrossRef]

22. Crespo, J.; Falqui, A.; García-Barrasa, J.; López-de-Luzuriaga, J.M.; Monge, M.; Olmos, M.E.; Rodríguez-Castillo, M.; Sestu, M.; Soulantica, K. Synthesis and plasmonic properties of monodisperse $\mathrm{Au}-\mathrm{Ag}$ alloy nanoparticles of different compositions from a single-source organometallic precursor. J. Mater. Chem. C 2014, 2, 2975-2984. [CrossRef]

23. Crespo, J.; García-Barrasa, J.; López-de-Luzuriaga, J.M.; Monge, M.; Olmos, M.E.; Sáenz, Y.; Torres, C. Organometallic approach to polymer-protected antibacterial silver nanoparticles: Optimal nanoparticle size-selection for bacteria interaction. J. Nanoparticle Res. 2012, 14, 1281. [CrossRef]

24. Fernández, E.J.; López-de-Luzuriaga, J.M.; Monge, M.; Olmos, M.E.; Puelles, R.C.; Laguna, A.; Mohamed, A.A.; Fackler, J.P., Jr. Vapochromic Behavior of $\left\{\mathrm{Ag}_{2}\left(\mathrm{Et}_{2} \mathrm{O}\right)_{2}\left[\mathrm{Au}\left(\mathrm{C}_{6} \mathrm{~F}_{5}\right)_{2}\right]_{2}\right\}_{n}$ with Volatile Organic Compounds. Inorg. Chem. 2008, 47, 8069-8076. [CrossRef]

25. Yan, S.C.; Li, Z.S.; Zou, Z.G. Photodegradation performance of $\mathrm{g}-\mathrm{C}_{3} \mathrm{~N}_{4}$ fabricated by directly heating melamine. Langmuir 2009, 25, 10397-10401. [CrossRef] [PubMed]

26. An, N.; Zhao, Y.; Mao, Z.; Agrawal, D.K.; Wang, D. Microwave modification of surface hydroxyl density for g-C3N4 with enhanced photocatalytic activity. Mater. Res. Express 2018, 5, 035502. [CrossRef]

27. Thomas, A.; Fischer, A.; Goettmann, F.; Antonietti, M.; Muller, J.-O.; Schlogl, R.; Carlsson, J.M. Graphitic carbon nitride materials: Variation of structure and morphology and their use as metal-free catalysts. J. Mater. Chem. 2008, 18, 4893-4908. [CrossRef]

28. Fina, F.; Ménard, H.; Irvine, J.T.S. The effect of $\mathrm{Pt}$ NPs crystallinity and distributionon the photocatalytic activity of $\mathrm{Pt}-\mathrm{g}-\mathrm{C}_{3} \mathrm{~N}_{4}$. Phys. Chem. Chem. Phys. 2015, 17, 13929-13936. [CrossRef] [PubMed]

29. Caux, M.; Menard, H.; AlSalik, Y.M.; Irvine, J.T.S.; Idriss, H. Photo-catalytic hydrogen production over Au/g-C $\mathrm{N}_{4}$ : Effect of gold particle dispersion and morphology. Phys. Chem. Chem. Phys. 2019, 21, 15974-15987. [CrossRef]

30. Fujigaya, T.; Kim, C.; Hamasaki, Y.; Nakashima, N. Growth and Deposition of Au Nanoclusters on Polymer-wrapped Graphene and Their Oxygen Reduction Activity. Sci. Rep. 2016, 6, 21314. [CrossRef] [PubMed]

31. Haidari, H.; Goswami, N.L.; Bright, R.; Kopecki, Z.; Cowin, A.J.; Garga, S.; Vasilev, K. The interplay between size and valence state on the antibacterial activity of sub-10 nm silver nanoparticles. Nanoscale Adv. 2019, 1, 2365-2371. [CrossRef]

32. Kreibig, U.; Vollmer, M. Optical Properties of Metal Clusters; Springer: Berlin, Germany, 1995.

33. Crespo, J.; López-de-Luzuriaga, J.M.; Monge, M.; Elena Olmos, M.; Rodríguez-Castillo, M.; Cormary, B.; Soulantica, K.; Sestu, M.; Falqui, A. The spontaneous formation and plasmonic properties of ultrathin gold-silver nanorods and nanowires stabilized in oleic acid. Chem. Commun. 2015, 51, 16691-16694. [CrossRef]

34. Crespo, J.; Guari, Y.; Ibarra, A.; Larionova, J.; Lasanta, T.; Laurencin, D.; López-de-Luzuriaga, J.M.; Monge, M.; Olmos, M.E.; Richeter, S. Ultrasmall NHC-coated gold nanoparticles obtained through solvent free thermolysis of organometallic Au(i) complexes. Dalton Trans. 2014, 43, 15713-15718. [CrossRef]

35. López-de-Luzuriaga, J.M.; Monge, M.; Quintana, J.; Rodríguez-Castillo, M. Single-step assembly of gold nanoparticles into plasmonic colloidosomes at the interface of oleic acid nanodroplets. Nanoscale Adv. 2021, 3, 198-205. [CrossRef]

36. Yang, Z.; Yan, J.; Lian, J.; Xu, H.; She, X.; Li, H. g- $\mathrm{C}_{3} \mathrm{~N}_{4} / \mathrm{TiO}_{2}$ Nanocomposites for degradation of ciprofloxacin under visible light irradiation. ChemistrySelect 2016, 1, 5679-5685. [CrossRef]

37. Wang, H.; Li, J.; Ma, C.; Guan, Q.; Lu, Z.; Huo, P.; Yan, Y. Melamine modified P25 with heating method and enhanced the photocatalytic activity on degradation of ciprofloxacin. App. Surf. Sci. 2015, 329, 17-22. [CrossRef]

38. Hao, R.; Wang, G.; Tang, H.; Sun, L.; Xu, C.; Han, D. Template-free preparation of macro/mesoporous g- $\mathrm{C}_{3} \mathrm{~N}_{4} / \mathrm{TiO}_{2}$ heterojuction photocatalysts with enhanced visible light photocatalytic activity. Appl. Catal. B Environ. 2016, 187, 47-58. [CrossRef]

39. Lu, N.; Wang, P.; Su, Y.; Yu, H.; Liu, N.; Quan, X. Construction of Z-Scheme g- $\mathrm{C}_{3} \mathrm{~N}_{4} / \mathrm{RGO} / \mathrm{WO}_{3}$ with in situ photoreduced graphene oxide as electron mediator for efficient photocatalytic degradation of ciprofloxacin. Chemosphere 2019, 215, 444-453. [CrossRef]

40. Chen, S.; Hu, Y.; Meng, S.; Fu, X. Study on the separation mechanisms of photogenerated electrons and holes for composite photocatalyst g- $\mathrm{C}_{3} \mathrm{~N}_{4}-\mathrm{WO}_{3}$. Appl. Catal. B Environ. 2014, 150-151, 564-573. [CrossRef]

41. Zhang, W.; Zhou, Z.; Shi, J.; Deng, H. Fabrication of novel visible-light-driven AgI/g-C3N4 composites with enhanced visible-light photocatalytic activity for diclofenac degradation. J. Colloid Interface Sci. 2017, 496, 167-176. [CrossRef] [PubMed]

42. Pattnaik, S.P.; Behera, A.; Martha, S.; Acharya, R.; Parida, K. Facile synthesis of exfoliated graphitic carbon nitride for photocatalytic degradation of ciprofloxacin under solar irradiation. J. Mater. Sci. 2019, 54, 5726-5742. [CrossRef] 